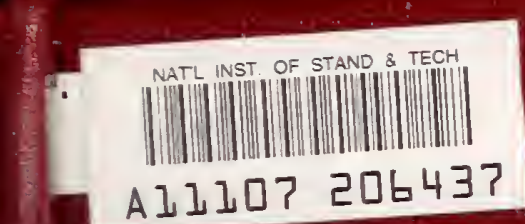








\section{Alll03 05637?}

NATL INST OF STANDARDS \& TECH R.I.C.

EN A11103056377

Paftenbarger, George/Organizations engag
QC100 U U N7 NO.577, 1980 C. 1 NBS-PUB.C

$x-5$

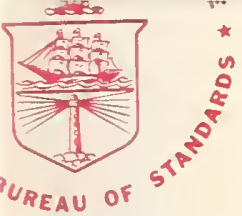

NBS SPECIAL PUBLICATION

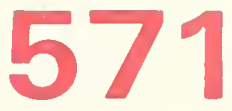

U.S. DEPARTMENT OF COMMERCE / National Bureau of Standards

National Bureau of Standards

Library, E.0l Admin. Bldg.

DCT 11981

191087

(i)

Organizations Engaged in Preparing Standards for Dental Materials and Therapeutic Agents with a List of Standards 


\section{NATIONAL BUREAU OF STANDARDS}

The National Bureau of Standards' was established by an act of Congress on March 3, 1901. The Bureau's overall goal is to strengthen and advance the Nation's science and technology and facilitate their effective application for public benefit. To this end, the Bureau conducts research and provides: (1) a basis for the Nation's physical measurement system, (2) scientific and technological services for industry and government, (3) a technical basis for equity in trade, and (4) technical services to promote public safety. The Bureau's technical work is performed by the National Measurement Laboratory, the National Engineering Laboratory, and the Institute for Computer Sciences and Technology.

THE NATIONAL MEASUREMENT LABORATORY provides the national system of physical and chemical and materials measurement; coordinates the system with measurement systems of other nations and furnishes essential services leading to accurate and uniform physical and chemical measurement throughout the Nation's scientific community, industry, and commerce; conducts materials research leading to improved methods of measurement, standards, and data on the properties of materials needed by industry, commerce, educational institutions, and Government; provides advisory and research services to other Government agencies; develops, produces, and distributes Standard Reference Materials; and provides calibration services. The Laboratory consists of the following centers:

Absolute Physical Quantities ${ }^{2}$ - Radiation Research - Thermodynamics and Molecular Science — Analytical Chemistry — Materials Science.

THE NATIONAL ENGINEERING LABORATORY provides technology and technical services to the public and private sectors to address national needs and to solve national problems; conducts research in engineering and applied science in support of these efforts; builds and maintains competence in the necessary disciplines required to carry out this research and technical service; develops engineering data and measurement capabilities; provides engineering measurement traceability services; develops test methods and proposes engineering standards and code changes; develops and proposes new engineering practices; and develops and improves mechanisms to transfer results of its research to the ultimate user. The Laboratory consists of the following centers:

Applied Mathematics - Electronics and Electrical Engineering ${ }^{2}$ - Mechanical Engineering and Process Technology ${ }^{2}-$ Building Technology - Fire Research Consumer Product Technology — Field Methods.

THE INSTITUTE FOR COMPUTER SCIENCES AND TECHNOLOGY conducts research and provides scientific and technical services to aid Federal agencies in the selection, acquisition, application, and use of computer technology to improve effectiveness and economy in Government operations in accordance with Public Law 89-306 (40 U.S.C. 759), relevant Executive Orders, and other directives; carries out this mission by managing the Federal Information Processing Standards Program, developing Federal ADP standards guidelines, and managing Federal participation in ADP voluntary standardization activities; provides scientific and technological advisory services and assistance to Federal agencies; and provides the technical foundation for computer-related policies of the Federal Government. The Institute consists of the following centers:

Programming Science and Technology- Computer Systems Engineering.

'Headquarters and Laboratories at Gaithersburg, MD, unless otherwise noted; mailing address Washington, DC 20234.

${ }^{2}$ Some divisions within the center are located at Boulder, CO 80303. 

for Dental Materials and Therapeutic Agents with a List of Standards

G. C. Paffenbarger, D.D.S.

R. W. Rupp, D.D.S., M.S.

Margaret Malmstedt

American Dental Association Health

Foundation Research Unit at the

National Bureau of Standards

Washington, D.C. 20234

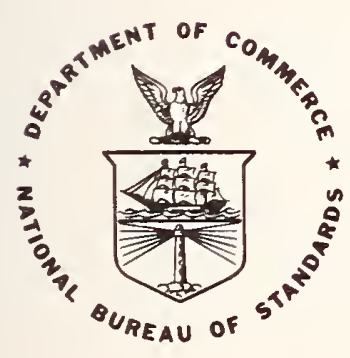

t Guecial Puhlication

U.S. DEPARTMENT OF COMMERCE, Philip M. Klutznick, Secretary

Luther H. Hodges, Jr., Deputy Secretary

Jordan J. Baruch, Assistant Secretary for Productivity, Technology, and Innovation

NATIONAL BUREAU OF STANDARDS, Ernest Ambler, Director

Issued April 1980 
Library of Congress Catalog Card Number: $80-600041$

National Bureau of Standards Special Publication 571

Nat. Bur. Stand. (U.S.), Spec. Publ. 571,55 pages (Apr. 1980)

CODEN: XNBSAV

For sale by the Superintendent of Documents, U.S. Government Printing Office, Washington, D.C. 20402 Stock No. 003-003-02163-6 Price $\$ 3.50$

(Add 25 percent for other than U.S. mailing.) 


\section{CONTENTS}

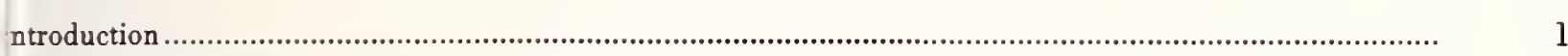

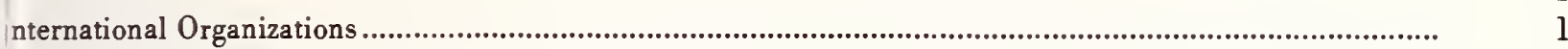

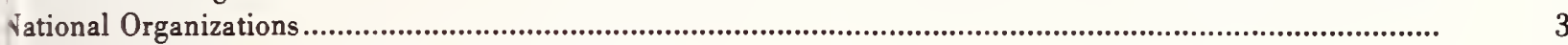

ndex to World Dental Specifications and Standards ..........................................................................

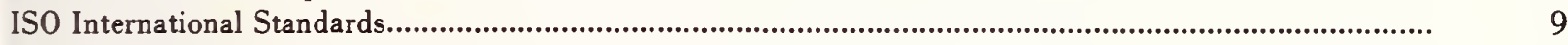

List of Draft International Standards (DIS) and Draft Proposals (DPs) Which Are

Being Prepared by ISO/TC106-Dentistry.

American National Standards Institute (ANSI)/

American Dental Association (ADA) Specifications .....................................................................

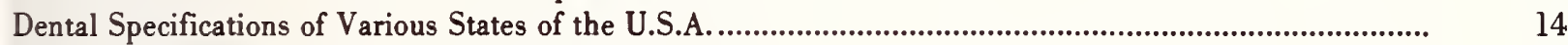

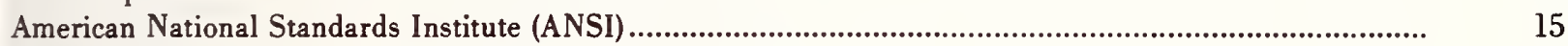

Dental Federal and Military Specifications and Standards ..................................................................

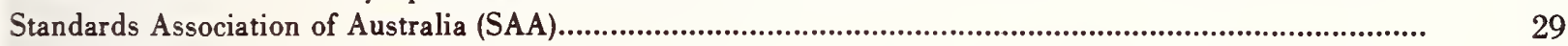

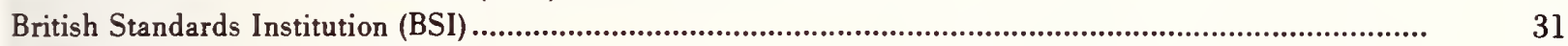

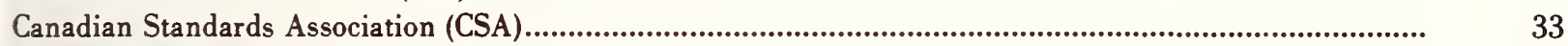

Czechoslovakian Society for Standardization and Measuring (CSN) ....................................................

French Standards Association (AFNOR) ................................................................................

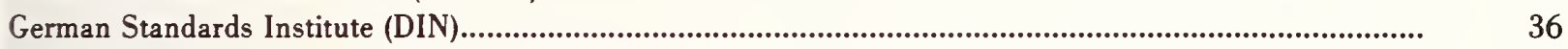

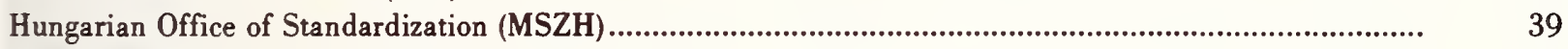

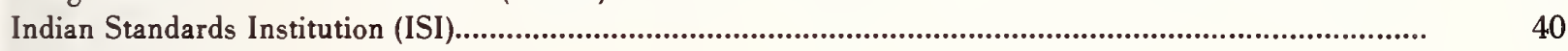

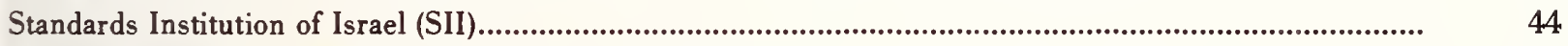

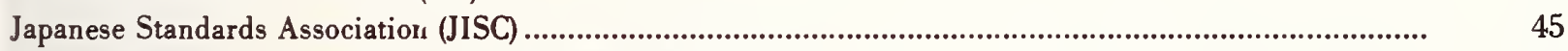

Polish Committee of Standardization and Measures (PKN).................................................................

South African Bureau of Standards (SABS) ...................................................................................

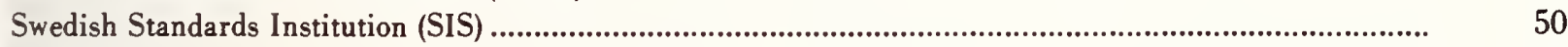

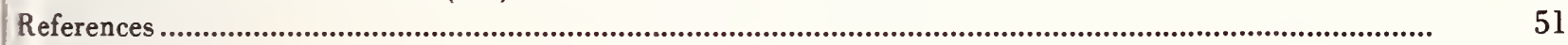





\title{
ORGANIZATIONS ENGAGED IN PREPARING STANDARDS FOR DENTAL MATERIALS AND THERAPEUTIC AGENTS WITH A LIST OF STANDARDS
}

\author{
G. C. Paffenbarger, D.D.S.*, N. W. Rupp, D.D.S., M.S.*, and Margaret Malmstedt ${ }^{* *}$
}

\begin{abstract}
The first specification for dental materials was prepared by Dr. Wilmer Souder, a physicist at the National Bureau of Standards, in 1927. From this stemmed the specification and certification programs of the American Dental Association (1930) and all of the similar national and international programs.

The Federation Dentaire Internationale (FDI) was the first in the international field (1953). Today the International Organization for Standardization (ISO) through its Technical Committee 106-Dentistry, organized in 1963, is the prime international agency formulating specifications for dental materials and devices. The FDl role by agreement with ISO/TC106 is the preparation of standards on clinical evaluations, on biological test methodology, on the preparation of informative reports on dental materials and therapeutic agents and on the proper methods of using them.

Today there are 15 international and national agencies that have prepared about 900 specifications for dental materials and devices. These agencies and their addresses are listed, with a brief history of each, together with a list of the specifications and standards that they have promulgated.
\end{abstract}

Key words: Dental agencies, devices; history, materials; programs; specifications.

\section{Introduction}

This survey was made at the request of the Commission on Dental Materials, Instruments, Equipment and Therapeutics (COMIET) of the Federation Dentaire Internationale and is really a revision of a former survey made in 1965 (Paffenbarger and Kumpula, 1965).

The survey of the extant specifications for dental materials, instruments and equipment manifests the tremendous growth in such standardization since November 30, 1925 when the first specification for a dental materials was promulgated (Souder, 1927). This was the United States Government Master Specification for Dental Amalgam Alloy, Specification No. 356, prepared by Dr. Wilmer Souder, a physicist at the National Bureau of Standards in Washington, D.C., U.S.A. This specification stemmed from an earlier investigation by Souder and Peters conducted in 1919 (Souder and Peters, 1920) because of a War Department request to the National Bureau of Standards for assistance in specifying the quality of amalgam that could be used in Army procurement.

-Research Associates for the American Dental Association Health Foundation Research Unit at the National Bureau of Standards, W ashington, D.C. 20234.

*Administrative Assistant, American Dental Association Health Foundation Research Unit at the National Bureau of Standards, W ashington, D.C. 20234.
From this activity stemmed the specification and certification programs of the American Dental Association (Taylor, 1930). This stimulated activity of a similar nature in Australia, Japan, the United Kingdom and other countries.

On the international scene the Federation Dentaire Internationale (FDI) organized an international specification program in 1953. After its development of two specifications, those for alloy for dental amalgam and for dental mercury, the FDI asked the International Organization for Standardization (ISO) in 1958 if ISO would consider FDI Specifications as ISO Standards. As a result ISO Technical Committee 106-Dentistry was formed.

\section{International Organizations}

International Organization for Standardization (ISO), 1 rue de Varembé, 1211 Genève 20, Switzerland.

ISO is an international yet nongovernmental organization that has as its object the development of worldwide standards which are published as ISO International Standards. These standards facilitate international exchange of goods and services and develop mutual cooperation in intellectual, scientific, technological and economic activities. The ISO members are 84 national standardization bodies, the most representative one from each country. Annual contributions from each of these member bodies enable the ISO to fulfill its function. 
More than 70 percent of these national standards bodies are either governmental institutions or organizations incorporated by public law. There are 8 countries in which ISO standards are mandatory; in 37 countries the ISO standards are mandatory to some extent; and in 20 countries the use of ISO standards is voluntary. These figures reflect the influence essentially of private control in many ISO member bodies which are supported in whole or in part by government subsidies. ISO has 154 technical committees that prepare draft ISO International Standards in the specific fields assigned to them. When a technical committee has reached agreement on a draft standard, the ISO Secretary General sends it to all member bodies for comment and suggestions which are forwarded to the pertinent technical committee. After careful consideration of any comments, the standard is sent to the Council, ISO's Board of Directors, for adoption as an ISO International Standard.

The ISO Technical Committee for Dentistry, formed in 1963, is ISO/TC106-Dentistry, with the British Standards Institution as the secretariat. ISO/TC106 has as its scope: "Standardization of terminology, methods of test and specifications applicable to materials, instruments, appliances and equipment used in all branches of dentistry." ISO/TC106 has formed six working groups on: (1) filling materials (Canada-Secretariat), (2) denture materials (U.S.A.-Secretariat), (3) terminology (France-Secretariat), (4) instruments and equipment (Germany-Secretariat), (5) classification of dental equipment (Germany-Secretariat), and (6) working space of the dentist (France-Secretariat). Australia, Canada, Czechoslovakia, Denmark, France, Germany, India, Ireland, Italy, Netherlands, Norway, Republic of South Africa, Sweden, Switzerland, United Kingdom, Union of Soviet Socialist Republics, and United States of America are participating members with 21 other member countries with observer status.

Federation Dentaire Internationale (FDI), 64 Wimpole Street, London W1M, 8AL, United Kingdom.

The FDI, founded in Paris in 1900, is a voluntary international federation of 78 national dental associations and has also individual supporting members. A Standing Commission on Dental Materials, Instruments, Equipment and Therapeutics (COMIET) has 15 members and has the responsibility of standardization in the various categories given in its title. Five members are technical representatives from the dental industry and were recommended by dental trade associations in the U.S.A., Europe and Asia.

The nine FDl specifications were adopted in 1966 as ISO Recommendations. Thereafter a close working relationship developed between the FDI and
ISO/TC106-Dentistry by the formation of several Joint Working Groups for specific tasks. The Chairman of the COMIET of the FDI also serves as a member of the governing body of ISO/TC106.

The FDI and ISO have gradually phased out the Joint Working Groups with the ISO/TC106 assuming the responsibility for the ISO International Standards and the FDI becoming responsible for standards on clinical evaluations, on biological test methodology and evaluations, on preparation of informative reports and on proper methods of using materials.

Dental terminology is also a joint undertaking between ISO/TC106 and the FDI, through its Commission on Classification and Statistics for Oral Conditions. This Commission's Working Group No. 5-Intercommission Group on Uniform Definitions of Dental Terams (INCOGUDET) and ISO/TC106 Working Group 3, with the collaboration of related international agencies, are responsible for the joint adoption of definitions. ISO/TC106-Dentistry, ISO/TC42-

Photography and ISO/TC84-Syringes for Medical Use and Needles for Injection, have also collaborated with the FDI in their respective fields.

The FDI developed a Uniform System of Tooth Designation which has been adopted by several national and international organizations.

As a result of the cooperation with the ISO, the FDI no longer issues specifications of its own.

The International Electrotechnical Commission, through its Technical Committee 62 and the FDI, have a joint Working Group in Dental Radiology with the FDI's COMIET which has formulated a draft standard, Radiation Protection and Equipment for Dental Radiology, Document IEC/SC 62B-JWGFDI/COMIET-(Secretary) 15, dated December 7, 1977.

Comité Européen de Normalisation (CEN), Rue Bréderode 2, B-1000 Bruxelles, Belgium.

CEN, the European Committee for Standardization, is an international scientific nonprofit association of the national standardization organizations of European countries operating since 1961 to formulate European standards (EN).

The membership of CEN is comprised of EEC and EFTA countries. Its main objective is to reduce trade barriers between these two organizations which may arise for technical reasons.

Technical Committee 55-Dentistry, the Secretariat of which is the British Standards Institution (BSI), has as its scope the formulation of European Dental Standards.

Members of CEN are also members of ISO and support ISO work. Where ISO Standards, which are 
suitable for adoption as European Standards, are available, they are edited in accordance with CEN rules to produce official texts in English, French and German. These three are technically and editorially identical. In other cases CEN establishes its own standards.

CENCER (CEN Certification) is the European organization for certification responsible for promoting the CEN quality mark and for controlling its application. The primary objective of CEN/TC55 is to develop a European certification scheme for dental products. The development of European Standards, where necessary, is to some extent secondary to that objective.

\section{Scandinavian Institute of Dental Materials}

(Nordisk Institutt for Odontologisk Materialprovning) (NIOM), Forskningsvn. 1, Oslo 3, Norway.

The Scandinavian Institute of Dental Materials (NIOM) was formally established in 1969 , by agreement among the governments of Denmark, Finland, Norway and Sweden. The aims of the lnstitute are to test and do research on dental materials and devices and to ascertain that the products employed in dental practice in the Scandinavian countries are optimal and fulfill any requirements which are put forward in international standards or by legislation.

The lnstitute is governed by a Board of Directors which comprises one member and an alternate member from each of the participating countries. It is financed, like other Scandinavian institutes, by a proportion corresponding to the gross national product of each country. Presently Sweden covers about 43 percent, Denmark 23 percent, Norway 17 percent and Finland 16 percent. These percentages are adjusted every second year. From 1978 lceland participates and covers about 1 percent of the budget. Apart from a small administrative unit, NIOM is divided into a physical/chemical division and a biological/clinical division. This recognition of both physical/chemical and biological/clinical aspects makes NIOM unique as a testing institution for dental materials.

The staff of the Institute has been appointed gradually during 1973-1977. Presently, 23 people are employed by NlOM, 15 in the physical/chemical division, 5 in the biological/clinical division and 3 in the administrative unit.

All testing is performed according to ISO Standards, which presently only cover physical/chemical properties of dental materials. The need for biological and clinical assessment of dental materials and instruments is generally accepted, and important standardization work is required to establish biological and clinical testing programs. NIOM is actively engaged in this work, by participating in the standardization performed by FDI, ISO and CEN.

\section{European Working Party on Dental Therapeutics (EAZA).}

The European Working Party on Dental Therapeutics was active (1963-1969) in promoting cooperation among the commissions on dental therapeutics of European Dental Organizations. In 1969 the work of EAZA was merged into the Working Group on Therapeutics of the Commission on Dental Materials, Instruments, Equipment and Therapeutics of the Federation Dentaire Internationale.

World Health Organization (WHO), 1211 Genève, Switzerland.

WHO interests in standardization center principally in the International Pharmacopoeia (Specifications for the Quality Control of Pharmaceutical Preparations).

\section{National Organizations}

There are several American (U.S.A.) governmental and nongovernmental agencies which are engaged in standardization work on dental items.

American Dental Association (ADA), 211 East Chicago Avenue, Chicago, Ill. 60611.

The American Dental Association, a dues-paying member of the American National Standards Institute (ANSI), has had a specification program for dental materials since 1930. This and the certification and acceptance programs for dental materials and devices are conducted under the auspices of the ADA Council on Dental Materials and Devices. The ADA serves as the administrative sponsor and pays for the cost of the Secretariat of AN Standards Committee MD 156 for Dental Materials and Devices. Specifications formulated by this AN Standards Committee are usually adopted both by the American Dental Association and the American National Standards lnstitute, but this pattern is not mandatory.

Lists of Certified Dental Materials and Devices, a program related to the specification activity, have been in operation for almost 5 decades. These lists are based upon certification by a manufacturer that his product complies with the pertinent specification and upon check testing done in the laboratories of the Association. The manufacturer must give evidence of quality control and agree to adhere to the advertising and exhibiting code of the Association. Check testing of products on the lists is a continuing process, and those products not complying are removed from the list. 
An acceptance program applies to materials and devices for which evidence of safety and usefulness has been established by biological, laboratory and/or clinical evaluations and where standards and specifications are not available. Categories include acceptable, provisionally acceptable and unacceptable products.

Status reports on dental materials, devices and techniques to assist the dentist in evaluating their safety and efficacy are developed by the Council on the basis of extant knowledge.

A 300-page book, GUIDE TO DENTAL MATERIALS AND DEVICES, is prepared biannually.

The American Dental Association has maintained since 1930 an extensive program in dental therapeutics under the auspices of its Council on Dental Therapeutics. This Council's annual publication, ACCEPTED DENTAL THERAPEUTICS, an extensive monograph of 342 pages, is now in its 37 th edition. It deals with drugs used in dental practice and includes a list of brands accepted by the Council on Dental Therapeutics of the American Dental Association. The Association maintains a Division of Chemistry housed in the Chicago offices of the Association as an investigative and research arm of the Council. The Council also has a grants-in-aid program for the development of desired information about products used in dental health service.

\section{American National Standards Institute (ANSI),} 1430 Broadway, New York, N.Y. 10018.

The American National Standards Institute, the U.S.A. member of ISO, is a federation of companies and of trade, technical, professional, consumer and labor organizations. There are about 185 organizational members and 880 company members as of June 1978. The ANSI dental standards are formed under the Committee Method for developing evidence of consensus for approval of American National Standards. The Council on Dental Materials and Devices of the American Dental Association serves as the Secretariat of American National Standards Committee MD 156 for Dental Materials and Devices.

American Society for Testing and Materials (ASTM), 1916 Race Street, Philadelphia, Pa. 19103.

The American Society for Testing and Materials is an international nonprofit society for the promotion of knowledge of the materials of engineering and the standardization of specifications and methods of testing. The worldwide membership of over 26,000 combines individual and organization members, several thousand being companies, institutions and agencies and shows the broad spectrum of its membership. Since 1898, the society has grown to a system of more than 130 technical committees composed of producers, consumers and general interest groups. The 1976 edition of ASTM Standards, containing over 32,000 pages and including over 5,000 ASTM Standards, reflects the vast important work of the society.

The ASTM has no dental materials committee but has dental representation on its Committee F-4 on Medical and Surgical Materials and Devices, F-19 on Orthotics, External Prosthetics and Mobility Aids, and F.8 on Protective Equipment for Sports. Committee F-4, has formulated over 40 specifications, test methods and recommended practices dealing with orthopedic, neurosurgical and cardiovascular materials and devices. Over 350 manufacturers, physicians, surgeons, bioengineers, biologists and governmental representatives are developing over 90 draft standards within eight F-4 subcommittes.

The Defense Medical Materiel Board. This Board, in the Department of Defense of the United States of America, is composed of personnel from the Army, the Navy and the Air Force. The three military dental services are represented by a senior dental officer whose term as a member of the board is rotated among the services. The board is the sole agency empowered to add items to, delete items from or modify items in the Federal Supply Catalog, Department of Defense, Medical Materiel. This catalog lists about 11,500 items, and about 1,000 of these are dental items. Procurement of these items is supported by either a Federal Specification, a Military Specification, or a Purchase Description. These specifications are prepared by the board on information obtained principally from the manufacturers of the items but supplemented with information available in the literature and extant specifications and regulations of various government agencies and professional and technical societies.

The Index of Federal Specifications and Standards, as established by the Federal Supply Service of the General Services Administration, references about 180 Federal Specifications of dental interest in the 1964 edition.

The Food and Drug Administration (FDA), Dept. of Health, Education and Welfare, has its administrative headquarters and major scientific facilities in the Washington, D.C. area. Additional laboratory and inspection facilities are located in 21 district offices throughout the United States.

The major responsibilities of the Food and Drug Administration are the enforcement of the Federal Food, Drug, and Cosmetic Act and the Radiation Control for Health and Safety Act and portions of the Public Health Service Act. The medical device amendments to the 
FD\&C Act (May 1976) gave FDA regulatory authority over medical devices comparable to that exercised in the area of new drugs.

The Federal Food, Drug, and Cosmetic Act of 1938, as amended, prohibits the shipment in interstate commerce of adulterated or misbranded foods, drugs, derices and cosmetics. Drugs and devices are misbranded if their labeling is false or misleading in any particular, or if the labeling fails to bear adequate directions for use or adequate warnings or they are a danger to health when used, etc. The Act prohibits the introduction into interstate commerce of any new drug or medical device prior to approval of an application establishing their safety and effectiveness. Applications are required to establish the safety and effectiveness of a new drug or new medical device for use as recommended in the labeling. Antibiotic drugs are subject to testing and certification on a batch basis to assure their safety and effectiveness. The premarketing clearance requirements for new drugs and antibiotics and devices apply to those used in dentistry as well as other areas.

Specifications and laboratory test procedures for antibiotic drugs, including dental preparations, are published as part of the regulations issued by FDA. In the case of new drugs, manufacturers are required to submit proposed specifications and laboratory test procedures and an application may not be approved until these are found to be adequate.

The Federal Food, Drug, and Cosmetic Act recognizes the specifications and test methods in the United States Pharmacopoeia, National Formulary, and Homeopathic Pharmacopoeia as official standards for drugs. Drugs that are not recognized as official drugs in the official compendia are regarded as adulterated if their identity, strength, purity or quality differs from that which they purport or are represented to possess. Since the Drug Amendments of 1962, drugs have also been regarded as adulterated if the methods, facilities or controls used for their manufacture, processing, packing or holding fail to conform with current good manufacturing practice to assure their safety and integrity. The Medical Device Amendments of 1976 provide similar requirements for devices. These provisions of the law also apply to drugs and devices used in dentistry.

The Medical Device Amendments of 1976 are designed to protect the public and health professionals from unsafe and ineffective devices and at the same time not to discourage innovation in medical and dental technology by unnecessary or overly burdensome restrictions. The new amendments make distinctions between those devices which present little risk to health and those which are intricate life sustaining and life supporting or are of substantial importance in preventing impairment of human health.

The Medical Device Amendments of 1976 recognize the need for the widest range of scientific expertise to assist in the regulatory process. It prohibits the marketing of new devices until their safety and efficacy have been established. The FDA now has the authority to remove dangerous devices from the market expeditiously.

Medical devices are classified on the basis of the degree of regulation necessary to assure safety and effectiveness as follows: Class I, general controls; Class II, performance standards; Class III, premarket approval.

FDA can exempt a device, if it is intended solely for investigational use, and if the necessary protection of patients is instituted through an agency review committee where such exist. Most provisions of the Amendments relating to medical devices become effective upon enactment, although many such provisions do not become enforceable regulatory requirements until regulations promulgated by the FDA become effective. The first regulations to implement the new law are given in "Implementation of the Medical Device Amendments of 1976" Federal Register 41:22620-22621 (June 4, 1976).

The Food and Drug Administration has an active program involving inspection of drug and device manufacturing establishments and the collection and laboratory examination of drugs and devices on the market. To assure the integrity of the drug and device supply, the law makes provisions for seizure, injunction, and criminal prosecution to deal with drugs and devices in violation of the Act.

\section{Dental Standards in Australia-Australian Organizations Involved in Standards for Dental} Materials. Australian dental standards are formulated by the appropriate dental technical committee of the Standards Association of Australia, Standards House, 80-86 Arthur Street, North Sydney, N.S.W. 2060, in response to requests from any reasonable source, provided that an inquiry shows that the proposed standards are warranted. The technical committees are composed of representatives drawn from all major interests associated with the particular subjects for which standards are being prepared. These generally include users, purchasing bodies, manufacturers, suppliers, regulatory bodies, research and testing organizations.

The Australian Dental Standards Laboratory, 240 Langridge Street, Abbotsford, Victoria 3067, generally carries out the technical work for the preparation of dental and allied standards, because of the expertise and 
testing facilities it possesses. The Laboratory was established in 1936 and became a function of the Australian Department of Health in 1947. Until 1973 it was known as the Commonwealth Bureau of Dental Standards.

The Australian Dental Association, 116 Pacific Highway, North Sydney, N.S.W. 2060, Standing Committee on Tariffs, Instruments, Materials and Equipment adopts the standards for use in connection with its program for accreditation of dental products, lists of which are published periodically. Samples are tested at the Australian Dental Standards Laboratory for compliance with the appropriate standard, for which service a nominal charge is made.

Australia is closely involved with ISO and FDI with the objective of developing International Standards.

British Standards Institution (BSI), 2 Park Street, London W1A, 2BS, United Kingdom.

The BSI represents the UK member Body of ISO and is the oldest among the National Standards Organizations tracing its origin back to the Engineering Standards Committee formed in 1901. BSI holds the Secretariat for ISO/TC106-Dentistry and that of the Organization for Standardization Technical Committee CEN/TC55-Dental Products. To date some 30 British Standards for dental items have been published, many of which are in several Parts. The formulation of these standards is carried out by various technical committees responsible to the BSI Dental Standards Committee with expertise being provided by representatives of the British Dental Association and other health professional societies, the British Dental Trade Association, various government departments including the Laboratory of the Government Chemist, various dental schools and universities and a number of individual co-opted experts. There is a comprehensive approvals program for dental materials currently being operated in the UK by the Department of Health with the Laboratory of the Government Chemist providing the specification testing facilities. This program applies to dental materials used in the National Health Service, and British Standards are the routine reference specifications.

Canadian Standards Association (CSA), 178 Rexdale Boulevard, Rexdale, Ontario M9W 1R3, Canada.

The CSA is a nonprofit, independent organization engaged in developing standards and certifying to standards. Its corporate mission is: "Services in Support of Voluntary Standardization."

Subsequent to the organization of the Health Care Technology Program in 1973, the Technical Committee on Dentistry was formed "to develop standards for procedures (other than clinical procedures), materials, devices and equipment used in the practice of dentistry with the object of assuring the safety and welfare of patients and dental personnel and the performance of products." The Committee also participates as the Canadian Advisory Committee for TC106-Dentistry of the International Organization for Standardization.

To date the Technical Committee has formed four subcommittees to survey and prepare standards for such matters as filling materials, prosthetic materials, terminology and instruments. Though, as yet, dental standards have not been published, the development of standards is progressing rapidly. It is expected that the standards prepared by these subcommittees will be based primarily upon relevant ISO and American standards with suitable revisions for Canadian applications, if necessary.

The Czechoslovakian Society for Standardization and Measuring (Úrad Pro Normalizaci a Merení) (CSN), Václavské Namesti 19, Praha-1-Nové Mesto, Czechoslovakia.

This organization has developed seven specifications since the first one was promulgated in 1955. One specification deals with terminology of tools, apparatus, and appliances for dentistry, one for instruments and five for materials. These standards are obligatory.

French Standards Association (Association Francaise de Normalisation) (AFNOR), Tour Europe, Cedex 7, 92080 Paris, La Defense, France.

The French Standards Association, founded in 1926, filled the gap left by the Permanent Standardization Commission (CPS). CPS instituted itself in 1918. AFNOR has always been a private, nonprofit organization which was recognized as a public service by a 1943 decree. Its membership consists of government authorities, scientific and technical societies, industrial and commercial associations, private firms and individuals. About 99 percent of AFNOR's 10,000 National Standards are voluntary. Twenty-eight deal with dentistry through the National Committee, Art Dentaire.

German Standards Institute (Deutsches Institut für Normung e.V. Normenausschusse Dental) (DIN), Westliche 56, 7530 Pforzheim, W. Germany, is the central body responsible for standardization in Germany. Since 1917 standardization is in progress in Germany and more than 15,000 standards exist. Membership in DIN is voluntary and not a pre-condition for participation in working groups. DIN is a nongovernmental institute with very little subsidy by the government. 
The Normenausschuss Dental, with its secretariat at 7530 Pforzheim, Westliche 56, W. Germany, is responsible for standardization in the field of dentistry. DIN by Normenausschuss Dental is the official and only representative of Germany in international standardization bodies, particularly in ISO. Working results of about 15 national working groups of Normenausschuss Dental are laid down and published in about 70 DIN standards. These standards may be ordered through Beuth-Verlag, Burggrafenstrasse $4-10,1000$ Berlin 30 , or any national standards institute.

\section{Hungarian Standards Association (Magyar} Szábranyügyi Hivatal) (MSZH), U1101-UT-25, Budapest IX, Hungary.

This agency has formulated 32 specifications for dental instruments. A separate specification is given for each handheld instrument. Less than 20 percent of the standards are compulsory.

Indian Standards Institution (ISI), Manak Bhavan, 9 Bahadur Shah Zafar Marg, New Delhi, 110 002, India.

This institution, established in 1947, is sustained principally by subscribing members in different categories, and by a grant-in-aid from the Government of India. ISI has published over 9,000 standards since its inception. Most of these standards are used by governmental agencies at all levels, commercial organizations and other public and private undertakings.

Standards Institution of Israel (SII), University Street, Tel Aviv, Israel.

This institution has three specifications dealing with dentistry, dental casting gold alloy and tooth brushes.

Japanese Industrial Standards Committee (JISC), Agency of Industrial Science and Technology, Ministry of International Trade and lndustry, 3-1, Kasumigaseki, Chiyoda-ku, Tokyo, Japan.

This committee in the government Agency of Industrial Science and Technology has 29 divisions, including one for the formulation of specifications for medical instruments and apparatus. This medical division has delegates from the health professions, manufacturers, government, officials and researchers. The actual work of preparing the specifications is carried on by a committee formed to work out a specification for a particular type of material or instrument. This committee's composition includes dentists, manufacturers and researchers. The recommendations of each committee go through channels until they reach the
Minister of Welfare who makes them official Japanese Industrial Standards (JIS). There are at present 30 kinds of dental materials and 32 items of dental apparatus for which JIS status has been granted.

Polish Committee of Standardization and Measures (Polski Komitet Normalizacji i Miar) (PKN), 00-139 Warszawa, ul. Elektoraina 2, Poland.

This committee gives the following information on standardization of dental items.

The series of standards in dentistry, worked up in Poland, contains national standards lettered PN and branch standards lettered BN. National standards relate to classification, nomenclature, marking, parameters and features of production quality having general and particularly valid significance. They are mandatory throughout the country. BN standards have the character of civil standards but they are mandatory in the narrower domain of application, and in the smaller range. They relate to the problems of standardization of definite products.

The standards related to dentistry are developed by Research-Development Centre of Medical Technics"ORMED." The national standards are definitely established by Polish Committee of Standardization and Measures which runs the whole standardization work in Poland.

South African Bureau of Standards (SABS), Dr. Lategan Road, Groenkloof, Private Bag X191, Pretoria, Republic of South Africa.

SABS assumed the task of standardization at its founding in 1945 by an Act of Parliament. Its operating funds stem from a parliamentary grant, fees from testing, inspection and certification schemes and sales of publications.

For some of the products listed only government purchasing (CKS) specifications are available, while for others national standard (SABS) specifications are available. The latter are generally more comprehensive and in addition to normal use can form the basis of certification marking schemes.

Swedish Standards Institution (Standardiseringskommissionen i Sverige) (SIS), Box 3295, S-103 66 STOCKHOLM, Tegnergatan 11, Sweden.

SIS does not for the time being publish any standards on dental materials but is channeling and coordinating the Swedish participation in ISO/TC106-Dentistry.

The Swedish Planning and Rationalization Institute of the Health and Social Services (Spri), Fack, S-102 50, Stockholm, Sweden, does publish specificationsSwedish hospital standards-for dental equipment, in- 
struments and materials. Spri is closely associated with SIS and takes part actively in the work of ISO/TC106Dentistry.

By agreement among the governments of Denmark, Finland, Norway and Sweden, the Scandinavian Institute of Dental Materials (NIOM) has been formed for testing, certification and research regarding dental materials and equipment to be used in the four countries. For this task ISO International Standards are used to the greatest possible extent.

\section{Extant Specifications for Dental Materials}

A listing of the current specifications for dental materials throughout the world shows the following:

\begin{tabular}{lc}
\hline \multicolumn{1}{c}{ Organization } & $\begin{array}{c}\text { Number of } \\
\text { Specifications }\end{array}$ \\
\hline Federation Dentaire Internationale (FDI) & Uses ISO Standards \\
International Organization for Standardization (ISO) & 24 \\
American Dental Association (ADA) & 65 \\
Dental Specifications of Various States of the U.S.A. & 10 \\
American National Standards Institute (ANSI) & 34 \\
Defense Medical Materiel Board (DMMB) (U.S.A.) & $334^{*}$ \\
Standards Association of Australia (SAA) & 54 \\
British Standards Institution (BSI) & 30 \\
Canadian Standards Association (CSA) & 9 \\
Czechoslovakian Society for Standardization and Measuring (CSN) & 7 \\
French Standards Association (AFNOR) & 29 \\
German Standards Institute (DIN) & 66 \\
Hungarian Office of Standardization (MSZH) & 27 \\
Indian Standards Institution (ISI) & 135 \\
Standards Institution of Israel (SII) & 3 \\
Japanese Standards Association (JISC) & 63 \\
Polish Committee of Standardization and Measures (PKNIM) & 45 \\
South African Bureau of Standards (SABS) & 21 \\
Swedish Planning and Rationalization Institute (Spri) & 61 \\
\hline
\end{tabular}

* Many dental items such as paper and cotton products, etc, are not included. 


\section{Index to World Dental Specifications and Standards}

Each national ISO Member Body serves, within its country, as the sole sales agent and information center for international specifications and for specifications of other national standardizing bodies, as well as for its own national specifications.

ISO INTERNATIONAL STANDARDS

\begin{tabular}{|c|c|}
\hline Title & ISO Number \\
\hline Alloy for dental amalgam & ISO $1559-1978$ \\
\hline Dental mercury & ISO $1560-1975$ \\
\hline Dental inlay casting wax & ISO $1561-1975$ \\
\hline Dental casting gold alloys & ISO $1562-1976$ \\
\hline Alginate impression material & ISO $1563-1978$ \\
\hline Agar impression material & ISO $1564-1976$ \\
\hline Dental silicate cement (hand mixed) & ISO $1565 \cdot 1978$ \\
\hline Dental zinc phosphate cement & ISO $1566-1978$ \\
\hline Dental base resin & ISO $1567-1978$ \\
\hline Dental burs and cutters-Fitting dimensions & ISO $1797 \cdot 1976$ \\
\hline $\begin{array}{r}\text { Dental vocabulary-List l: Basic terms } \\
\text { Bilingual edition }\end{array}$ & ISO $1942 / 1-1977$ \\
\hline $\begin{array}{l}\text { Dental vocabulary - List 2: Dental materials } \\
\text { Bilingual edition }\end{array}$ & ISO $1942 / 2-1977$ \\
\hline $\begin{array}{c}\text { Dental vocabulary - List 3: Dental instruments and equipment } \\
\text { Bilingual edition }\end{array}$ & ISO $1942 / 3-1977$ \\
\hline $\begin{array}{l}\text { Dental vocabulary - List } 4: \text { Terms associated with testing of dental } \\
\text { materials, instruments and equipment } \\
\text { Bilingual edition }\end{array}$ & ISO $1942 / 4-1976$ \\
\hline $\begin{array}{l}\text { Dental burs and cutters-Nominal sizes and designation } \\
\text { of working parts }\end{array}$ & ISO 2157-1972 \\
\hline Dental zinc oxide/eugenol filling materials & ISO $3106-1974$ \\
\hline Dental zinc oxide-eugenol cementing materials & ISO $3107-1974$ \\
\hline Dentistry-Working space of the dentist-Definitions and principles & ISO $3246-1977$ \\
\hline Dentistry_Synthetic resin teeth & ISO $3336-1977$ \\
\hline Dental silicophosphate cement (hand-mixed) & ISO $3824-1977$ \\
\hline Capsulated dental silicate and silico-phosphate filling materials & ISO $3851 \cdot 1977$ \\
\hline Tooth designation for dental purposes-Two-digit system & ISO $3950-1977$ \\
\hline Dental handpieces-Coupling dimensions & ISO $3964-1977$ \\
\hline Resin-based dental filling materials & ISO $4049 \cdot 1978$ \\
\hline
\end{tabular}




\begin{tabular}{|c|c|}
\hline Title & Number \\
\hline $\begin{array}{l}\text { Revision of } 1463-1973 \\
\text { Metallic and Oxide Coatings-Measurement of Coating } \\
\text { Thickness-Microscopical Method }\end{array}$ & DP 1463 \\
\hline $\begin{array}{l}\text { Revision of } 1562-1976 \\
\text { Dental Casting Gold Alloys }\end{array}$ & DP 1562 \\
\hline Addendum 1 to $1942 / 1$ & DAD $1942 / 1$ \\
\hline Addendum 2 to $1942 / 1$ & DAD $1942 / 1$ \\
\hline Addendum 1 to $1942 / 2$ & DAD $1942 / 2$ \\
\hline $\begin{array}{l}\text { Dental Vocabulary-List 3: Dental Instruments and } \\
\text { Equipment-Addendum } 1\end{array}$ & DAD $1942 / 3$ \\
\hline Addendum 2 to $1942 / 3$ & DAD $1942 / 3$ \\
\hline $\begin{array}{l}\text { Addendum } 1 \text { to } 1942 / 3-1977 \\
\text { Dental Vocabulary-List 3: Dental Instruments and Equipm }\end{array}$ & DAD $1942 / 3$ \\
\hline Addendum 1 to $1942 / 4$ & DAD $1942 / 4$ \\
\hline $\begin{array}{l}\text { Dental Root Canal Instruments-Part 1: } \\
\text { Nominal Sizes, Dimensions and Colour Coding for } \\
\text { Reamers and Files }\end{array}$ & DIS $3630 / 1$ \\
\hline $\begin{array}{l}\text { Dental Root Canal Instruments-Part 2: } \\
\text { Files and Reamers }\end{array}$ & DP $3630 / 2$ \\
\hline $\begin{array}{l}\text { Dental Root Canal Instruments-Part 3: } \\
\text { Barbed Broaches and Rasps }\end{array}$ & DP $3630 / 3$ \\
\hline $\begin{array}{l}\text { Dental Root Canal Instruments-Part 4: } \\
\text { Paste Carriers }\end{array}$ & DP $3630 / 4$ \\
\hline $\begin{array}{l}\text { Dental Burs and Cutters-Dimensions of Working Parts and } \\
\text { Overall Length, Requirements for Run-out (Eccentricity } \\
\text { and Surface Roughness) }\end{array}$ & DIS 3823 \\
\hline $\begin{array}{l}\text { Dental Equipment-Items of Dental Equipment } \\
\text { at the Working Place-Identification System }\end{array}$ & DIS 4073 \\
\hline Dental Operating Chair-General Requirements & DIS 4083 \\
\hline Dental Carboxylate Cement & DIS 4104 \\
\hline Elastomeric Dental Impression Materials & DIS 4823 \\
\hline Dentistry-Porcelain Teeth & DP 4824 \\
\hline Cobalt-Chromium Denture Base Materials & DP 4825 \\
\hline $\begin{array}{l}\text { Dental Rotary Instruments-Number Coding System-Part 1: } \\
\text { General Principles }\end{array}$ & DIS $6360 / 1$ \\
\hline $\begin{array}{l}\text { Dental Rotary Instruments-Number Coding System-Part 2: } \\
\text { Material of Working Part, and Coating or Binding }\end{array}$ & DIS $6360 / 2$ \\
\hline
\end{tabular}


Type of Shank and Handle, and Overall Length

Dental Rotary Instruments-Number Coding System-Part 4:

DP $6360 / 4$

Shape and Design

Denture Base Metal Casting Alloys

DP 6871

Dental Porcelain Powders

DP 6872

Dental Gypsum Products

DP 6873

Dental Pit and Fissure Sealants

DP 6874

Dental Patient Chair-Specification

DP 6875

Dental Root Canal Sealers

DP 6876

Endodontic Core Materials

DP 6877 


\section{Index to National Dental Specifications and Standards}

AMERICAN NATIONAL STANDARDS INSTITUTE (ANSI) AMERICAN DENTAL ASSOCIATION (ADA) SPECIFICATIONS*

Title

ADA Number

Alloy for Dental Amalgam

Specifications

Casting Investment for Dental Gold Alloy

Dental Impression Compound

Dental Inlay Casting Wax

Dental Casting Gold Alloy

Dental Mercury

Dental Wrought Gold Wire Alloy

Dental Zinc Phosphate Cement

Dental Silicate Cement

Dental Agar Impression Material

Denture Base Polymers

Denture Cold-Curing Repair Resin

Dental Base Metal Casting Alloys

Acrylic Resin Teeth

Dental Impression Paste-Zinc Oxide-Eugenol Type

Denture Base Temporary Relining Resin

Dental Alginate Impression Material

Elastomeric Dental Impression Material

Dental Duplicating Material

Dental Zinc Silico-Phosphate Cement

Intraoral Dental Radiographic Film

Dental Excavating Burs

Dental Base Plate Wax

Dental Gypsum Products

Dental X-Ray Equipment and Accessory Devices

Direct Filling Resins

Endodontic Files and Reamers

Hand Instruments

Proposed-Dental Explorers

Zinc Oxide-Eugenol Type Restorative Materials

Exposure Time Designations for Timers of Dental X-Ray Machines 
Proposed:

$\begin{array}{ll}\text { Handpieces } & 35\end{array}$

$\begin{array}{ll}\text { Dental Diamond Rotary Cutting Instruments } & 36\end{array}$

$\begin{array}{ll}\text { Dental Abrasive Powders } & 37\end{array}$

$\begin{array}{ll}\text { Porcelain-Metal Systems } & 38\end{array}$

$\begin{array}{lr}\text { Pit and Fissure Sealants } & 39\end{array}$

$\begin{array}{ll}\text { Dental Implants } & \mathbf{4 0}\end{array}$

ANSI/ADA Document No. 41 for Recommended Standard Practices for Biological Evaluation Dental Materials

Proposed:

Phosphate-Bonded Investments $\quad 42$

Mechanical Amalgamators $\quad 43$

Dental Electrosurgical Equipment $\quad 44$

Porcelain Teeth $\quad 45$

$\begin{array}{lr}\text { Chairs } & 46\end{array}$

$\begin{array}{ll}\text { Units } & 47\end{array}$

$\begin{array}{lr}\text { Ultraviolet Activator and Disclosing Lights } & \mathbf{4 8}\end{array}$

$\begin{array}{lr}\text { Analgesia-Anesthesia Equipment } & 49\end{array}$

$\begin{array}{lr}\text { Casting Machines } & \mathbf{5 0}\end{array}$

$\begin{array}{ll}\text { Gas Furnaces } & 51\end{array}$

ANSI/ADA Uranium Content in Dental Porcelain and Porcelain Teeth 52

Proposed:

Crown and Bridge Plastics $\quad 53$

$\begin{array}{ll}\text { Needles } & 54\end{array}$

Dispensers of Alloy and Mercury for Dental Amalgam $\quad 55$

$\begin{array}{ll}\text { Dental Floss } & 56\end{array}$

$\begin{array}{ll}\text { Endodontic Filling Materials } & 57\end{array}$

$\begin{array}{lr}\text { Hedstrom Files, Rasps and Barbed Broaches } & \mathbf{5 8}\end{array}$

$\begin{array}{lr}\text { Sterilizers } & 59\end{array}$

$\begin{array}{lr}\text { Jet Injectors } & 60\end{array}$

Zinc Polycarboxylate Cement $\quad 61$

$\begin{array}{lr}\text { Dental Abrasive Pastes } & 62\end{array}$

\section{Standards}

Shapes, head dimensions and shank dimensions for Dental Diamond rotary instruments

Recommended standard practices for clinical research protocol for dental materials and devices

Dental terminology

\section{Recommendations}

For mercury surveys of dental offices

In radiographic practices

In mercury hygiene

-These specifications, standards and recommendations are available from the American Dental Association, 211 East Chicago Avenue, Chicago, III. 60611, U.S.A. 
DENTAL SPECIFICATIONS OF VARIOUS STATES OF THE U.S.A.

Some states in the U.S.A., namely, New York, ${ }^{*}$ New Jersey, ${ }^{*}$ and Pennsylvania*** have dental specifications as follows:

\begin{tabular}{clr}
\hline State & \multicolumn{1}{c}{ Title } & Number \\
\hline NY & Automatic Dental Film Processor (X-Ray) (University) (1971) & $11001-0716$ \\
NY & Panoramic Dental X-Ray System and Related Accessories (Hospital) & $11001-0559$ \\
NY & Stationary Extra and Intra Oral Full Mouth Dental X-Ray System & $11001-0865$ \\
& $\quad$ (Medical Center) (1968) & $11001-0867$ \\
NY & Split Assembly Dental X-Ray Unit (Psychiatric Institute) (1971) & $11001-0886$ \\
NY & Wall Mounted Dental X-Ray Unit (1968) & $11001-0851$ \\
NY & Mobile Dental X-Ray Unit (1969) & 13 \\
NJ & Medical and Dental X-Ray Film (X-26) (1969) & $9932-02 \mathrm{~A}$ \\
NJ & Dentistry (1968), Specification for Laundry Service & $9932-02 \mathrm{~A}$ \\
NJ & New Jersey College of Medicine and Dentistry (1968) (Catalogue) & D-25 \\
Pa & Dentrifice (Therapeutic) for Dental Hygiene (1971) USC Ps50
\end{tabular}

*Director of Purchasing, Division of Purchasing, Office of General Services, 119 Washington Avenue, Albany, N.Y. 11225

** Division of Purchase and Property, Department of the Treasury, State House, Trenton, N.J. 08625

***Secretary of Property and Supplies, Department of Property and Supplies, Room 602, North Office Building, Harrisburg, Pa. 17125 
Dental Materials, Specifications for:

Alloy for Dental Amalgam (ADA Spec No. 1) (Agrees with ISO 1559) (redesignation of Z156.1·1972)

Casting Investment for Dental Gold Alloy (ADA Spec No. 2) with Addendum MD156.2a-1965 (R 1975) (redesignation of Z156.2-1962 and Z156.2a-1965)

Dental Impression Compound (ADA Spec No. 3) with Addendum MD156.3a-1965 (R1975) (redesignation of Z156.3-1962 and Z156.3a-1965)

Dental Inlay Casting Wax (ADA Spec No. 4) (Agrees with ISO 1561) (revision and redesignation of Z156.4-1962)

MD156.1-1972

Dental Casting Gold Alloy (ADA Spec No. 5) (redesignation of Z156.5-1972)

Dental Mercury (ADA Spec No. 6) (Agrees with $1 S 0$ 1560) (redesignation of Z156.6-1962)

MD156.2-1962

(R1975)

MD156.3-1962

(R1975)

MD156.4-1975

MD156.5-1972

Dental Wrought Gold Wire Alloy (ADA Spec No. 7) (Agrees with ISO 1562) with Addendum MD156.7a-1965 (R1975) (redesignation of Z156.7-1962 and Z156.7a-1965)

Dental Zinc Phosphate Cement (ADA Spec No. 8) (redesignation of Z156.8-1972)

Dental Silicate Cement (ADA Spec No. 9) (Agrees with ISO 1565) (redesignation of Z156.9-1963)

MD156.6-1962

(R1975)

MD156.7-1962

(R1975)

MD156.8-1972

MD156.9-1963 (R1975)

Dental Agar Impression Material (ADA Spec No. 11) (redesignation

MD156.11-1972 of Z156.11-1972)

Denture Base Polymers (ADA Spec No. 12) (Agrees with ISO 1567)

MD156.12-1965 (revision and redesignation of Z156.12.1965) (R1975)

Denture Cold Curing Repair Resin (ADA Spec No. 13) (redesignation of Z156.13-1962)

MD156.13-1962 (R1975)

Dental Chromium-Cobalt Casting Alloy (ADA Spec No. 14) with

MD156.14-1962 Addendum MD156.14a-1965 (R1975) (redesignation of (R1975) Z156.14-1962 and MD156.14a-1965)

Acrylic Resin Teeth (ADA Spec No. 15) with Addendum MD156.15a-1965

MD156.15-1962 (R1975) (redesignation of MD156.15-1962 and Z156.15a-1965)

(R1975)

Dental Impression Paste, Zinc Oxide-Eugenol Type (ADA Spec No. 16) with Addendum MD156.16a-1965 (R1975) (redesignation of

MD156.16-1962 of Z156.16-1962 and Z156.16a-1965)

(R1975)

Denture Base Temporary Relining Resin (ADA Spec No. 17) with

MD156.17-1962 Addendum MD156.17a-1965 (R1975) (redesignation of (R1975) Z156.17-1962 and Z156.17a-1965)

MD156.18-1972

Alginate Impression Material (ADA Spec No. 18) (redesignation of Z156.18-1972) 
Dental Duplicating Material (ADA Spec No. 20)

MD156.20-1972 (redesignation of Z156.20-1972)

Dental Zinc Silico-Phosphate Cement (ADA Spec No. 21)

MD156.21-1972 redesignation of Z156.21-1972)

Intraoral Dental Radiographic Film (ADA Spec No. 22)

PH8.1

Dental Excavating Burs (ADA Spec No. 23) (revision, redesignation

MD156.23-1975 and consolidation of Z122.2-1966 and Z156.23-1972)

Dental Base Plate Wax (ADA Spec No. 24) (redesignation of Z156.24-1972)

Dental Gypsum Products (ADA Spec No. 25) (redesignation of Z156.25-1972)

Dental X-Ray Equipment (ADA Spec No. 26)

MD156.26-1975

Direct Filling Resins (ADA Spec No. 27)

MD156.27-1976

Root Canal Files and Reamers (ADA Spec No. 28)

MD156.28-1976

Hand Instruments, Dental: General Specifications for (ADA Spec No. 29)

MD156.29.1976

Dental Zinc Oxide-Eugenol Restorative Materials (ADA Spec No. 30)

MD156.30-1977

Exposure Time Designations for Timers of Dental X-Ray Machines

MD156.31-1975 (Reaffirmation of PH6.4-1970) (ADA Spec No. 31)

Orthodontic Wire Not Containing Precious Metals

MD156.32-1977 (ADA Spec No. 32)

Dental Terminology (ADA Spec No. 33)

MD156.33-1976

Dental Aspirating Syringes (ADA Spec No. 34)*

Size Designations and Dimensions for Intraoral

PH6.2-1970 Dental Radiographic Film (R1976)

Speed Classification for Intraoral Dental

PH6.1-1970 Radiographic Film

(R1976)

*Proposed

Copies may be obtained from:

The American National Standards Institute,

1430 Broadway, New York, N.Y. 10018, U.S.A. 
DENTAL FEDERAL AND MILITARY SPECIFICATIONS AND STANDARDS ${ }^{(1),(2)}$

\begin{tabular}{|c|c|c|c|}
\hline $\mathrm{FSC}^{(3)}$ & Title & Number & Date \\
\hline 6520 & Abrasive Paste, Dental, Validated Jul 74 & P.A-86A & 14. Aug 57 \\
\hline 6520 & Abrasive Paste, Dental & P-A-0086B & 17 Nov 70 \\
\hline 6520 & Abrasive, Dental, Powder & MIL-A-36826A & 15 Aug 78 \\
\hline 6520 & Amalgamator, Electric, Dental, Single Speed & MIL-A-37711 & 02 Jan 77 \\
\hline 6520 & Applicator Set, Pin Retention, Dental & MIL-A-36644 & $03 \mathrm{Mar} 70$ \\
\hline 6520 & $\begin{array}{l}\text { Arbor and Band Set, Dental Handpiece, } \\
\text { Validated Sep } 73\end{array}$ & GG-A-00671C & 23 Jan 67 \\
\hline 6520 & Articulator, Dental & GG.A-684 & 22 May 47 \\
\hline 6520 & Articulator, Dental & GG-A-00684A & 16 Oct 68 \\
\hline 6520 & $\begin{array}{l}\text { Articulator, Dental, Plain Line, Lingual } \\
\text { Access Design }\end{array}$ & MIL-A-37819A & 18 Aug 78 \\
\hline 6520 & $\begin{array}{l}\text { Bag, Dental Prosthesis, Plastic } \\
\text { Validated Sep } 73\end{array}$ & MIL-B-36528 & $10 \mathrm{Feb} 67$ \\
\hline 6520 & $\begin{array}{l}\text { Band Set, Copper, Dental and Copper Strip. } \\
\text { Dental, Validated Jul } 74\end{array}$ & RR-B.96B & $18 \mathrm{Jul} 57$ \\
\hline 6520 & $\begin{array}{l}\text { Band Set, Matrix, Dental, Strip, Matrix Dental, } \\
\text { and Band, Matrix, Dental }\end{array}$ & GG-B-0095D & 07 Jun 72 \\
\hline 6520 & $\begin{array}{l}\text { Band Set, Matrix, Dental, Strip, Matrix Dental } \\
\text { and Band, Matrix, Dental, Validated Oct } 69\end{array}$ & GG-B-95C & 10 Oct 62 \\
\hline 6520 & $\begin{array}{l}\text { Band, Abrasive (Silicon-carbide), for Dental } \\
\text { Lathes, Validated Jul } 74\end{array}$ & GG-B-89B & 04. Mar 58 \\
\hline 6520 & $\begin{array}{l}\text { Band, Abrasive (Silicon-carbide), } \\
\text { Validated Jul } 74\end{array}$ & GG.B.0089C & 09 Mar 67 \\
\hline 6520 & Band, Ligature, Dental, Rubber & ZZ-B·00117B & $12 \operatorname{Jan} 71$ \\
\hline 6520 & $\begin{array}{l}\text { Band, Ligature, Dental, Rubber, } \\
\text { Validated May } 72\end{array}$ & ZZ-B-117A & 04. Sep 58 \\
\hline 6520 & Bands and Strip, Copper, Dental & RR.B-0096C & 13 May 68 \\
\hline 6520 & Baseplate, Dental, Validated Jul 74 & GG.B.120A & 20 Sep 56 \\
\hline 6520 & Baseplate, Dental & GG.B.00120B & 16 Apr 69 \\
\hline 6520 & Basket, Cartridge, Dental Impression Material & MIL-B-36877 & $06 \mathrm{Jul} 72$ \\
\hline 6520 & $\begin{array}{l}\text { Bath, Water, Dental impression Compound, } \\
\text { Thermostatically Controlled }\end{array}$ & GG-B-00140C & 17 Sep 70 \\
\hline 6520 & $\begin{array}{l}\text { Bath, Water, Dental Impression Compound, } \\
\text { Thermostatically Controlled }\end{array}$ & GG-B-140A & 16 Apr 57 \\
\hline 6520 & $\begin{array}{l}\text { Bath, Water, Dental Impression Material, } \\
\text { Low Temperature }\end{array}$ & MIL-B-37295A & 17 Aug 78 \\
\hline 6520 & Blade and Flame, Dental Laboratory Die Saw & MIL-B-36411 & 15 Mar 65 \\
\hline
\end{tabular}



Validated May 66 Validated Jul 74 Validated Aug 69

ZZ-B-00616C

09 Dec 69

ZZ-B-616D

QQ-B-653B

GG-B-00686D

23 Aug 76

23 Mar 60

GG-B-686B

GG-B-00735A

GG-B-735

H-B-00185A

$13 \mathrm{Jul} 70$

H.B-185

GG-B-00750D

01 Nov 60

GG-B-750C

06 Nov 69

30 Apr 62

MIL-B.36170A

$24 \operatorname{Mar} 70$

H-B-248A

18 Dec 58

H-B-00248B

Bur, Dental, Validated Aug 64

Bur, Dental Surgery, Validated Jul 74 Tungsten Carbide 

Parts

6520 Cement, Zinc Oxide and Eugenol, Dental (Crown and Bridge)

6520 Cement, Zinc Oxide and Eugenol, Dental

MIL-C-36757A

$08 \operatorname{Sep} 76$ (Intermediate Restorative Material)

6520 Cement, Zinc Oxide and Polyacrylic Acid, Dental

MIL-C.36871

07 Jun 72

6520 Cement, Zinc Phosphate, Dental, Validated Jul 74

U-C-211A

13 Dec 56

6520 Cement, Zinc Phosphate, Dental

U-C-00211D

$06 \operatorname{Sep} 74$

6520 Chair, Rotary, Dental Prosthetic Laboratory

MIL-C-36173A

$11 \mathrm{Feb} 69$

6520 Chisel, Dental, Bone, Surgical

MIL-C-37741A

$15 \operatorname{Sep} 78$

6520 Chisel (Cutting Instruments), Dental, Carbon Steel

MIL.C.36804

09 Nov 71

6520 Chisel (Cutting Instruments), Dental

GG-C-001433B

12 Jul 76

6520 Chisel, Denture Trimming

GG-C-00289A

11 Sep 69

6520

Chisel, Denture Trimming, Laboratory,

GG-C.289

25 Oct 49 Validated Jul 74

6520 Clay, Modeling, 1/2 lb.

U-C-00451A

$28 \operatorname{Mar} 72$

6520 Clay, Modeling, Dental, Validated Jul 74

U-C-451

14. Jan 48

6520 Cloth, Sqeeuze, Dental

DDD-C-00475B

09 Jun 72

6520 Coating Plastic, Denture Model

MIL-C-36584.

$10 \mathrm{Jul} 69$

6520 Cone, Felt, Dental Grinding and Polishing Machine

GG-C-00576C

26 Jun 73

GG-C-576B

18 Mar 57 Polishing Machine, Validated Jul 74.

6520 Covers, Bracket Table, Dental, Paper

UU-C-611C

23 Jun 76

6520 Cup and Holder, Dental Waste, Validated Sep 73

6520 Cup, Dental Amalgam

MIL-C-36498

22 Jul 66

MIL-C-36843A

08 Feb 77 

Validated May 66

GG.D.195A

$04 \operatorname{Sep} 58$ Validated Jul 78

MIL-D-36776

16 Jul 71

6520 Disk, Plastic, Abrasive, Dental

MIL-D-36256

26 Jun 76

6520 Disk Set, Abrasive, Dental Handpiece (Disk, Abrasive, Mandrel, Dental Handpiece)

GG-D-00419D

21 Oct 76

6520 Disk Set, Abrasive, Dental Handpiece (Paper, with Stand)

GG-D-419D

21 Oct 76

6520 Disk, Abrasive, Silicon Carbide, Dental, Validated May 76

GG-D-00426B

17 Feb 69

6520 Disk, Abrasive, Silicon Carbide, Dental, Validated June 75

GG-D.426A

09 Jan 57

6520 Dispenser, Cotton Pellet, Dental, Validated Jun 75

GG-D-00444B

19 Jan 68

6520 Dispenser, Cotton Pellet, Dental, Validated Jun 75

GG-D-444A

19 Apr 57

6520 Dispenser, Dental Floss, Metal, Validated Sep 73

6520 Dispenser, Mercury, Dental

MIL-D-36242A

$20 \operatorname{Sep} 66$

GG.D-455

13 Sep 56

6520 Dispenser, Strip, Dental, Validated Jun 75

GG.D-00441C

30 Apr 69

6520 Dispenser, Strip, Dental, Validated Jun 75

GG.D.441B

MIL-D-37775A

01 May 57

6520 Drill, Pulp Canal, Dental, Gates-Glidden, Angle Handpiece

6520 Drill, Pin Hole, Dental

MIL-D-36786A

19 Sep 78

6520 Elevator, Dental, Surgical

GG.E-1161

14. Mar 74

6520 Excavator, Dental, Corrosion Resisting Steel

GG-E-1230B

26 Apr 67

6520 Excavator, Dental (Darby-Perry)

GG-E-001334

13 Jul 76

6520 Excavator, Dental, Carbon Steel

MIL-E-36803

04. May 67

6520 Explorer, Dental, Validated Jun 75

GG-E-916B

09 Nov 71

6520 Explorer, Dental

GG-E-00916E

26 Aug 57

6520 File and Reamer Set, Pulp Canal, Dental, Validated Jul 74

06 Apr 73

31 Jan 61 
6520 File, Pulp Canal, Dental, Hedstrom

MIL-F-36782

05 Aug 71

6520 Flashlight, Patient, Examining, Disposable

MIL-F-36678B

$22 \operatorname{Mar} 76$

6520 Flask, Denture, Crown and Bridge, Validated May 76

MIL-F-36585

03 Sep 69

6520 Flask, Denture, Upper and Lower, Ejector Type

MlL-F-36284A

07 Aug 68

6520 Floss and Tape, Dental, Waxed USER-GL 26 REV-EA

FFF-F-486B

28 Oct 76

6520 Floss, Waxed, Dental REV-EA

FFF-F-00486A

15 Feb 67

6520 Flux, Casting, Dental (Reducing)

O-F-501B

$25 \operatorname{Mar} 58$

6520 Forceps, Casting, Removing, Dental

MIL-F-36571B

$10 \mathrm{Jan} 77$

6520

Forceps, Dental Articulating Paper,

MIL-F-36176A

03 Oct 69

6520 Forceps, Dressing, Dental, Validated Jun 75

GG-F-599

02 May 68

6520 Forceps, Dressing, Dental

GG-F-00599A

05 Jan 70

6520 Forceps, Rubber Dam Clamp, Dental

MIL-F-36458A

17 Oct 72

6520 Forceps, Tooth Extracting, Validated Jul 74

GG-F-1240

13 Feb 68

6520 Forceps, Tooth Extracting, Validated Jul 78

GG-F-001240A

23 Aug 72

6520 Furnace, Dental Laboratory, Electric

W.F-7790

18 Nov 77

6520

Gingival Retraction Cord

MlL-G-36509C

04 Aug 78

6520 Gold Alloy, Casting, Dental

QQ-G-00540B

01 Feb 65

6520 Gold Foil, Cylinder, Dental

QQ-G-00545B

03 May 71

6520 Gold, Casting, Dental

QQ-G-540A(1)

11 Jun 59

6520 Gold, Foil, Cylinders (for dental fillings), Validated Jul 74

QQ-G-545(1)

30 Mar 51

OO-G-682

08 Aug 56 Validated Jul 78

6520 Grinding and Polishing Machine, Dental Laboratory, Bench Mounted, 115 Volt, 60 Cycle, AC

6520 Grinding and Polishing Machine, Dental Laboratory, Bench Mounted, High Speed, 110 Volt, 60 Cycle, AC, Validated Jul 75

6520 Grinding and Polishing Machine, Dental Laboratory, Floor Mounted, 110 Volt, 60 Cycle, AC, (Use in lieu of Fed Spec 00-G-684), Validated Jul 74 

Grip Chuck, Round Sleeve

MIL-H-36887(1)

Handpiece, Dental Laboratory, Straight High Speed, Belt Driven, Validated Jul 78

MIL-H-36794

03 Sep 71

6520 Handpiece, Dental, Right Angle, Prophylaxis, Round

MIL-H-36809B

$03 \operatorname{Mar} 77$ Sleeve, Screw Stem

6520 Handpiece, Dental, Contra-angle, Round Sleeve, Latch Type

Handpiece, Dental, Straight, Round Nose, Belt Driven, Validated Jul 78 Validated Jul 78 Hydrocolloid, Agar Type, Validated Jul 78

6520 Impression Material, Dental, Hydrocolloid, Agar Type, Validated Jul 78

6520 Impression Material, Dental, Hydrocolloid, Alginate Type

6520 Impression Material, Dental, Paste, Validated Jun 75 Type 

Type, Dental Validated Jul 78

6520 Knife, Margin Finishing, Dental, Baird Handle, Dental Instrument Point, Cone Socket, Validated May 76

6520 Knife, Plaster, Dental, Validated Jun 75

GG-K-00508C

08 Jan 69

6520 Knives, Dental, Craftman S. Compound, and Plaster

GG-K.508B

27 Mar 57

6520 Knives, Periodontal, Kirkland

MIL-K-36480

18 Apr 66

6520

Knives, Periodontal, Orban

MIL-K-36486A

03 Mar 69

6520 Light Set, Surgical, Overhead, Electric Shadow-reducing, Demountable (Naval Shipboard Use)

MIL-L-2034C

23 Jan 75

Lubricant, Silicate Cement, Dental, Validated Jul 78

P.L.00790A

$15 \operatorname{Jan} 71$

Lubricant, Silicate Cement, Dental,

P-L-790(1)

06 Feb 57 Validated Jun 75

Mallet, Oral Surgery

GG-M-105D

$18 \mathrm{Jul} 77$

6520 Mallet, Oral Surgery, Validated Jul 74

GG-M-00105C

02 Oct 64

6520 Mandrels, Dental Handpiece, Validated Jun 75

GG-M-108A

25 Sep 56

6520 Mandrels, Dental Handpiece

GG-M-00108D

04 Jun 73

Mat, Floor, Dental Chair, Rubber

ZZ-M-42

10 Apr 47

6520

Matrix Set, Dental, Plastic, Cervical, Validated July 78

MIL-M-36821

$13 \operatorname{Mar} 72$

6520 Medicine Glass

DD-M-00200B

13 May 70

6520 Mirror and Mirror Handle, Mouth Examining

GG-M-00431E

07 Oct 76

6520 Mirror and Mirror-light, Dental-REV-MB

MIL-M-36727B

23 Sep 78

6520 Mirror, Mouth Examining, REV.MI

GG-M-431E

07 Oct 76

6520 Mirror, Mouth Examining, Plastic, Plane

MIL-M-36552A

12 Apr 76 Glass, Disposable

6520 Mixer, Dental Casting Investment (Mechanical), Validated Jun 75

6520 Mixer, Dental Casting Investment (Mechanical) Validated Jun 75

6520 Mixing Pad, Parchment Paper, Dental

10 May 68

GG·M·500

12 Mar 57

GG-M-00515A
21 Dec 67 

Dressing

MIL-P-37920

31 Aug 78

6520 Pin, Tooth Die

MIL-P-36556A

$10 \mathrm{Jul} 76$

6520 Plaster, Dental Impression and Modeling

6520 Plastic Filling Instruments and ContourInstrument, Dental

SS-P-446D

27 May 75

GG-P-001278A

02 Jan 70

6520 Plastic Strip, Dental Matrix

L-P.525A

10 Feb 58

6520 Plastic Strip, Dental Matrix, Validated Jul 74

6520 Plastic Strip, Dental Surface Protection Mouthguard

6520 Plastic Strip, Denture Trial Pack, Validated Jul 78

6520 Platinum Foil (Dental), Validated Jul 74

L-P-00525B

MIL-P-36895

30 Nov 66

08 Nov 72

MIL-P-36464

29 Dec 65

QQ-P-00428C

28 Feb 67

6520 Platinum Foil (Dental), Validated Jul 78

QQ-P-428B(1)

09 Apr 57

6520 Plier, Dental No. 114, Johnson Design, Validated Jul 78

MIL-P-36892

24 Aug 72

6520 Pliers, Dental, Amalgam Reinforcement Pin, Validated Jul 78

MIL-P-36855

14. Jun 72

6520 Pliers, Dental, Contouring and Crimping No. 137

MIL-P.37361

04. Feb 74

6520 Pliers, Dental, Holding and Placing

MIL-P-37083

09 Apr 75

6520 Pliers, Dental, Steiglitz, 5 3/16 inches, Validated Jul 78

6520 Plugger, Amalgam, Dental, Markley, Validated Jul 78

MIL-P-36712

24. Sep 70

MIL-P.36577

$17 \mathrm{Jul} 69$

6520 Plugger, Plastic Filling, Dental, Glick

MIL-P-36959

$22 \operatorname{Mar} 73$

6520 Plugger, Pulp Canal

GG-P-00481D

13 Apr 73

6520 Plugger Set, Plastic Filling, Dental

6520 Point Assortment, Pulp Canal (Paper, Absorbent), Validated Jun 75

MIL-F-37717A

$28 \operatorname{Sep} 78$

GG-P.581B

21 Apr 58

6520 Point Assortment, Pulp Canal, Standardized, Silver

GG.P.1127A

24 Jun 75

6520 Points, Pulp Canal, Dental, Paper, Validated Jul 74

GG-P.00581D

18 Oct 73

6520

Press, Flask, Dental

15 Feb 73 
MIL-P-36671A

14 Apr 72

6520 Probes, Periodontal

MIL-P-36477A

19 Feb 76

6520 Probes, Periodontal

MIL-P.37928

27 Oct 78

6520 Protector, Denture, Model Plastic

MIL-P.37500

26 Apr 78

6520 Pulp Protector, Dental, Validated Sep 73

U.P.001250

01 Nov 66

6520 Pulp Protector, Dental, Calcium Hydroxide Paste

MIL-P.37088

$25 \operatorname{Mar} 75$

6520 Pulp Protector, Dental, Zinc Oxide and Eugenol

MIL-P.36705

19 Aug 70

6520 Pump, Filler (Aspirators) and Couplings, Validated Jul 74

GG-P-821 A

$09 \mathrm{Jul} 52$

6520

Punch, Dental, Rubber Dam

GG.P-850

25 Aug 60

6520 Punch, Dental, Rubber Dam

GG-P.00850A

13 Nov 68

6520 Remover, Dental Crown, Simplex

GG-R-001638

09 Apr 70

6520 Resin, Acrylic, Dental

U-R-00179A

20 Feb 67

652

Resin, Acrylic, Dental

U-R.179

15 Sep 54

6520 Resin, Acrylic, Dental, Fibered Denture Base Material

MIL-R-37770A

16 Sep 78

6520 Resin, Acrylic, Dental, Impression Tray Material

MIL-R-36433B

18 Apr 72

6520 Retainer, Matrix, Dental

GG.R-1472A

16 Jun 75

6520 Retractor, Tongue and Cheek-University of Minnesota

Rongeurs, Dental

GG-R.001549

21 Nov 68

6520 Rubber Dam, Dental

ZZ-R.00690A

19 Jun 68

6520 Rubber Dam, Dental, Validated Jul 74

ZZ·R 690

20 Aug 58

6520 Scaler, Dental, Morse

MIL-S-36186B

16 Sep 76

6520 Scaler, Dental, Single Ended

GG-S-001634

30 Jan 70

6520 Scissors, Collar and Crown

GG-S-001616

01 Sep 70

6520 Scissors, Oral Surgical

MIL-S-36456A

18 Feb 76

6520 Sealing Compound, Pulp Canal, Dental

U.S-00156C

17 Apr 73

6520 Separator, Teeth, Dental, Elliott, Curved Jaw

GG-S.00208A

$25 \operatorname{Mar} 69$

6520 Separator, Teeth, Dental, Elliott, Curved Jaw, Validated May 72

6520 Silver Alloy Pellet, Dental

GG-S.208

20 Sep 60

MIL-S-37708

28 Dec 76

DDD-S-496E

02 Oct 67

6523 Smocks, Dental Operating and Medical Assistant

MIL-S-36469A

26 Aug 66 
6520 Spatula, Dental, Cement

GG-S-00590A

12 Aug 69

6520 Spatula, Dental, Cement

GG-S-590B

21 Oct 76

6520 Spatula, Dental, No. 313

MIL-S-36793

09 Sep 71

6520 Spatula, Dental, Plastic

MIL-S-36697

22 Jun 70

6520 Splint Set, Arch Wire, Dental, Validated Jul 74

GG-S-00627B(1)

$08 \mathrm{Jul} 66$

6520 Splint, Jaw, Fracture, Arch Wire and Accessories (Dental)

GG-S-627A(1)

13 Dec 56

6520 Spreader, Gutta-percha, Dental, No. 3

MIL-S-36377A

08 Feb 77

6520

Stone, Artificial, Dental

U-S-746A

11 Oct 77

6520 Stone, Artificial, Dental

U-S-00746C(1)

12 Jun 70

6520 Stool, Dental Operating Chair, Mobile

MIL-S-36574

24 Jan 69

6520 Stopping, Temporary, Dental

MIL-S-36396

24 Feb 65

6520 Strip Assortment and Disks, Aluminum Oxide Abrasive, Safe-sided, Metal-backed, Dental

GG-S-00783C

$13 \operatorname{Mar} 70$

6520 Strip, Abrasive, Dental

GG-S-770

26 Aug 76

6520 Strip, Abrasive, Dental

MIL-S-36948

22 Feb 73

6520 Strip, Abrasive, Dental (Metal, Safe-sided) and Strip Assortment, Abrasive, Dental (Metal,

GG-S-783B(1)

$16 \mathrm{Jul} 58$ Safe-sided)

6520 Suction Apparatus, Dental

GG-S·00271

03 Aug 67

6520 Surveyor, Clasp, Dental

GG.S-805B

18 Nov 77

6520 Surveyor, Clasp, Dental, Validated Jul 74

GG-S-00805A

08 Feb 67

6520 Syringe, Air and Water, Dental

GG.S.00915A

04 Sep 70

6520 Syringe, Air, Dental, Validated Jul 74

GG.S.915

30 Dec 59

6520 Syringe, Dental Impression Material and

MIL-S-36894A

$07 \mathrm{Jul} 78$ Replacement Parts

6520 Template, Dental

MIL-T-36631

09 Mar 70

6520 Tin Foil (for Dental Use), Validated Jul 74

QQ-T-276

$18 \mathrm{Jul} 51$

8530 Toothbrushes (for Adults and Children)

H-F-560A

15 Sep 72

6520 Tooth Die Pin Placement Kit

MIL-T-36820

12 Apr 72

6520 Tracer, Gothic Arch, Dental, Validated May 72

MIL-T-36476

30 Mar 66

6520 Tray, Alloy Accessory, Dental Plastic

MIL-T-36729

09 Dec 70

6520 Tray, Impression, Dental, Validated Jul 74

GG-T-626

07 Mar 55

6520 Tray, lmpression, Dental

GG-T-00626A 
$21 \operatorname{Sep} 76$

6520 Vibrator, Dental Molding, 115 Volt, 60 Hertz AC

MlL-V.36372B

29 Jun 77

6520 Wax, Base-plate, Dental, Validated Jul 74

U.W.135B

15 Jan 76

Wax, Baseplate, Dental

U.W.00135A

26 Mar 70

Wax, Boxing, Dental, Validated Jul 74

U.W.138

12 May 47

Wax, Casting, Dental, Validated Jul 74

U.W.140

16 Mar 53

$19 \operatorname{Sep} 67$

Wax, Utility, Dental, Validated Jul 74

U.W.156

17 Aug 48

6520 Wedge Set, Dental, Matrix, Wood and Holder, Matrix Wedge, Contra-angle

MIL-W-36421B

$04 \operatorname{Mar} 77$

Wheel Abrasive, Aluminum Oxide

M1L-W-37584

21 Oct 76

Wheel Set, Abrasive, Aluminum Oxide, Mandrel-mounted, Dental

MIL-W-2129A

15 Aug 78

6520 Wheel Set, Abrasive, Rubber Points

MIL-W-37583

29 Jun 77

6520 Wheel, Abrasive (Silicon carbide, Mounted, Dental)

6520 Wheel, Abrasive, Impregnated Rubber, Pumice

6520 Wheel, Abrasive, Silicon Carbide

6520

Wheel, Abrasive, Silicon Carbide, Dental Model Trimming

6520

Wheel, Buffing, Chamois, Dental, Validated May 76

GG.W-239B

13 May 76

GG.W-00253A

$22 \operatorname{Jan} 73$

GG-W-239B

13 May 76

MIL-W-37013

01 Apr 74

6520 Wheel, Buffing, Cloth, Dental, Validated Jun 75

KK-W-266A

$08 \operatorname{Sep} 61$

GG-W-259A

22 Jul 59

6520 Wheel, Buffing, Cloth, Dental

GG.W.00259B

26 Apr 72

6520 Wheel, Lathe, Silicon carbide, Dental

GG.W.258

09 Oct 52

6520 Wire, Platinum Alloy

MIL-W.16193B

23 Sep 77

6520

Wire, Snare (Spring Steel, Medical),

GG.W-331

02 Nov 51 Validated Jun 75

17 Sep 73 

$90 \mathrm{kVp} 100.130$ Volt, $50.60 \mathrm{~Hz}$. AC

"'Federal Specifications may be purchased from:

General Services Administration, Specification and Consumer Information, Distribution Branch (3FRI), Washington Navy Yard, Building 197, Washington, D.C. 20407

(2) Military (MIL) Documents may be obtained from:

The Naval Publications and Forms Cenler, 5801 Tabor Avenue, Philadelphia, Pa. 19120

(.5) FSC (Federal Supply Catalog) 
Acrylic Denture Base Resin

1043-1971

Dental Chisels, Excavators, Probes and Scalers

1086-1971

Dimensions of Shanks and Chuck Fittings for Dental Rotary lnstruments

1093-1972

Dental Duplicating Material

1097-1972

Intra-Oral Dental X-ray Films (amended 1976)

1139-1971

Cold Processing Resins for Denture Repairs

1183-1977

Elastomeric Dental Impression Materials

1185-1972

Dental Zinc Phosphate Cement

$1186-1972$

Orthodontic Latex Elastic Bands

$1240-1973$

Dental Shellac Baseplates

1241-1973

Orthodontic Band Cements

$1253-1973$

Dental Gutta-Percha Points

1258-1977

Dental Single-Use Cartridge Hypodermic Needles (Sterile)

1264-1972

Dental Alginate Impression Material (amended 1974)

$1282-1972$

Dental Rubber Dam Punch

1283-1974

Dental Excavating Burs: Part I Basic Requirements including

$1373-1977$ Design and Dimensions

Dental Stainless Steel Root Canal Files and Reamers

1411.1976

Dental Operating Luminaires (Lights) for Oral lllumination

$1437-1976$

Dental Modelling Waxes

1453-1973

Dental Silicate and Silicophosphate Cements (amended 1977)

1454-1973

Dental Mercury

1581.1973

Dental Inlay Casting Waxes

$1582-1973$

Dental Sticky Wax

1583-1973

Dental Hypodermic Needles (Reusable)

1592-1974

Dental Artificial Stone

1616-1974

Dental Casting Golds

1620-1976

Dental Silver Solder

$1622-1976$

Dental Gold Solder

1623-1976

Dental Wrought Gold Alloys

1625-1976

Acrylic Teeth

1626-1974 
Dental Modelling Compounds

Dental Agar Impression Material

Dental Die Stone

Dental Impression Paste

Orthodontic Wires (Resilient)

Dental Zinc Oxide/Eugenol Restorative Materials

Alloy for Dental Amalgam

Dental Polycarboxylate Materials

Dental and Mobile Medical X-ray Machines

Under Revision:

Anaesthetics for Dental Injection

Dental Casting Investment

T22 -1963

Cobalt Chromium Casting Alloy

T28 -1964 
Specification for Dental Silicate Cement and Dental Silico-Phosphate Cement

Part 1-Silicate Cements

Part 2-Silico-Phosphate Cement

Part 3-Capsulated Cements

Specification for Dental Base Metal Casting Alloys

Part 1-Denture Base Alloys

Part 2-Inlay, Crown and Bridge Alloys

Specification for Dental Gold Solders

Specification for Dental Impression Compound

1965

Specification for Orthodontic Wire and Tape and Dental

Ligature Wire Made of Stainless Steel

1976

Specification for Dental Inlay Casting Wax

1962

Specification for Dental Wrought Precious Metal Alloy Wire

1962

Specification for Acrylic Resin Teeth

$1966^{* *}$

Specification for Doyen's Mouth Gag

1966

Specification for Dental Rotary Instruments

1967

Part 1-Dimensions of shanks and chuck fittings

Specification for Dimensions of the Transmission Coupling

(Slip-Joint) to Dental Handpieces

1967

Specification for Dental Mercury

Dental Elastic Impression Materials

Part 1-Elastomeric Impression Material

1968

Part 2-Alginate Impression Material

Dental Zinc Oxide-Eugenol Impression Materials

1968

Dental Casting Gold 'Alloy

1969

Glossary of Terms Relating to Dentistry

$1970^{*}$

Dental Impression Plaster

$1970^{*}$

Mouth Mirrors and Mouth Mirror Handles 
Dental Extracting Forceps (Performance Requirements)

Dental Artificial Stone

Toothpastes

Dental Casting Investments

Part 1-Gypsum Bonded Dental Casting Investments

Part 2-Phosphate Bonded Dental Casting Investments

Part 3-Ethyl Silicate Bonded Dental Casting Investments

Resin-Based Filling Materials

Popular Patterns of Dental Extracting Forceps

5211

Specification for Dental Porcelain for Jacket Crowns-about to be published.

*Under revision

**ISO Standard being adopted 


\begin{tabular}{|c|c|c|}
\hline Title & Number & $\begin{array}{l}\text { Published } \\
\text { or Revised }\end{array}$ \\
\hline $\begin{array}{l}\text { Dental Terminology and Definitions/Art } \\
\text { Dentaire-Terminologie et définitions }\end{array}$ & CAN3-Z349.1-79 & 1979 \\
\hline $\begin{array}{l}\text { Dental Burs and Cutters-Fitting Dimensions } \\
\text { (Adopted ISO 1797-1976, with editorial modification) }\end{array}$ & CAN3-Z349.2M79 & 1979 \\
\hline $\begin{array}{l}\text { Dental Inlay Casting Wax (Adopted ISO 1561-1975, } \\
\text { with editorial modification) }\end{array}$ & CAN3-Z349.4-M80 & At press \\
\hline $\begin{array}{l}\text { Dental Casting Gold Alloys (Adopted ISO 1562-1979, } \\
\text { with modification) }\end{array}$ & CAN3-Z349.5-M80 & At press \\
\hline $\begin{array}{l}\text { Tooth Designation for Dental Purposes-Two-Digit System } \\
\text { (Adopted ISO 3950-1977, with editorial modification) }\end{array}$ & CAN3-Z349.9-M80 & At press \\
\hline \multicolumn{3}{|c|}{ Related Standards } \\
\hline Construction and Test of X-Ray Equipment & C22.2 No. 114-1961 & 15.51 \\
\hline Electromedical Equipment & C22.2 No. 125-1979 & 1979 \\
\hline $\begin{array}{l}\text { Continuous Flow Anaesthetic Apparatus (Anaesthetic } \\
\text { Machines) for Medical Use }\end{array}$ & pZ168.3-1978 & 1978 \\
\hline Non-Flammable Medical Gas Piping Systems & Z305.1-1975 & 1975 \\
\hline \multicolumn{3}{|c|}{ Standards in Preparation } \\
\hline Dental Mercury & $\mathrm{Z} 349.3$ & 1980 \\
\hline Alginate Dental Impression Material & Z349.6 & 1980 \\
\hline Agar Impression Material & Z349.7 & 1980 \\
\hline Synthetic Resin Teeth & Z349.8 & 1980 \\
\hline
\end{tabular}

\section{CZECHOSLOVAKIAN SOCIETY FOR STANDARDIZATION AND MEASURING (CSN)}

\begin{tabular}{lc}
\hline \multicolumn{1}{c}{ Title } & CSN Number \\
\hline Terms of tools, apparatus and appliances for dental surgeons & 840006 \\
Connection of dental drills with handles & 857350 \\
Dental zinc phosphate cements & 665220 \\
Dental silicate cements & 665221 \\
Heat-cured acrylic resin for dental use & 665222 \\
Self-curing acrylic resin for dental use & 665223 \\
Casting investment for dental chrome alloy & 665224 \\
\hline
\end{tabular}


Vocabulary of dentistry-Basic terms

NF S 91-001*

Vocabulary of dentistry-Terms relating to dental products

NF S 91-002*

Vocabulary of dentistry-Terms relating to dental instruments and equipment

NF S $91-003^{*}$

Vocabulary of dentistry-Terms relating to tests for dental products, instruments and equipment

NF S 91-004*

Vocabulary of dentistry-Equivalence of English and French terms

NF S 91-010*

Method of tooth designation

NF S 91.011

The study of the working space of the dentist

NF S 91-012

Anthropometric characteristics concerning the working space of the dentist

NF S $91 \cdot 013$

Dental burs-interchangeability dimensions

NF S 91.101

Dental burs and cutters-Nominal sizes and designations of working parts

NF S 91.102

Reamers and files for root canals for use in dentistry-Part 1:

Nominal dimensions, designation and colour code

NF S 91-103

Coupling dimensions between handpieces and electric motors

NF S 91-104

Dental rotary instruments, number coding system-Part 1: General Principles

NF S 91-105*

Dental rotary instruments, number coding system-Part 2:

Material of working part and coating or binding

NF S 91-106*

Dental rotary instruments, number coding system-Part 3:

Type of shank and handle and overall length

NF S $91 \cdot 107^{*}$

Alloy for dental amalgam

S $91-201^{*}$

Dental mercury

NF S $91-202$

Dental inlay casting wax

NF S 91.203

Dental casting gold alloy

NF S 91-204

Alginate impression material

S 91-205*

Agar impression material

NF S 91-206

Dental silicate cement

S $91-207^{*}$

Dental zinc phosphate cement

S $91 \cdot 208^{*}$

Denture base polymer

S $91 \cdot 209^{*}$

Dental zinc silicophosphate cement (hand mixing)

S 91.210

Dental zinc oxide/eugenol filling materials

Dental zinc oxide/eugenol cementing materials

S $91-212$

Synthetic resin teeth

NF S 91-213* 
Silicate and silicophosphate based dental filling materials in capsules

NF S $91.214^{*}$

Resin-based dental filling materials

NF S 91.215

Carboxylate cements

NF S 91.216

*Actually in revision 
Dental materials; silicate cement; requirements, testing

Dental materials; zinc phosphate cements; requirements, testing

Dental materials; alloy for amalgam requirements, testing

Dental materials; mercury; requirements, testing

Dental materials; casting gold alloy; requirements, testing

Dental materials; denture base polymer; requirements, testing

Dentistry; designation of teeth

Dental materials; gypsum; requirements, testing

Dental materials; cobalt-chrome-casting alloy; requirements, testing

Dental materials; impression materials; requirements, testing

Dentistry; synthetic resin teeth; requirements, testing

Dental materials; silico-phosphate cements; requirements, testing

Dental instruments; toothbrushes, definitions, dimensions, requirements

Dental materials; capsulated silicate- and silico-phosphate cement; requirements, testing

Dental terminology; basic terms

13920

B1. 1

Dental terminology; dental materials

13920

B1. 2

Dental terminology; terms for dental instruments

13920

B1. 3

Dental terminology; testing of dental materials, instruments

13920 and equipment

B1. 4

Dentistry; porcelain teeth, requirements, testing

Dental materials; resin-based filling materials; requirements, testing

Dental equipment; identification of dental equipment at the working place

Dental materials; zinc oxide/eugenol cementing materials, filling materials; requirements, testing

Dental materials; zinc oxide/eugenol cementing materials for use in "permanent" cementation of dental restorations; requirements, testing

Dental instruments; coupling dimensions for handpiece-motors 
Dental instruments; burs and cutters; nominal sizes

Dental instruments; excavating burs, round

13951

B1. 1

Dental instruments; excavating burs, inverted cone

13951

B1. 2

Dental instruments; excavating burs, wheel

13951

B1. 3

Dental rotary instruments; excavating burs, pear head

13951

B1. 4

Dental instruments; fissure burs, cylinder square

13952

B1. 1

Dental instruments; fissure burs, cone square

13952

B1. 2

Dental instruments; finishing burs and burnishers, round

13953

B1. 1

Dental instruments; finishing burs and burnishers, oval

13953

B1. 2

Dental instruments; finishing burs and burnishers, bud

13953

Bl. 3

Dental instruments; finishings burs and burnishers, pear

13953

-

B1. 4

Dental instruments; finishing burs and burnishers, flame

13953

B1. 5

Dental instruments; root canal reamers, type $\mathrm{K}$

13960

Dental instruments; root canal files, type $\mathrm{K}$

13961

Dental instruments; root canal files, type $\mathrm{H}$ (Hedstroem-files)

13962

Dental instruments; root canal filler

13963

Dental instruments; rasps

13964

Dentistry; root canal filling points

13965

Dental instruments; barbed broaches

13966

Dental instruments; root canal instruments; terms and designations

13967

Teil 1

Dental instruments; root canal instruments; sizes and color-code

13967

Teil 2

Dental instruments; root canal instruments; measuring

13967

Teil 3

Dental instruments; explorers

13975

Dental instruments; carving instruments; type Hollenback

13976

Dental instruments; filling instruments, type Heidemann

Dental instruments; filling instruments

13978 
Dental instruments; scalers type McCall

Dental instruments; scalers type Darby-Perry

Dental instruments; scalers type Jaquette

Dental instruments; scalers with interchangeable points, handle

Dental instruments; scalers with interchangeable points,

13983 points type Morse

Teil 2

Dental instruments; excavating forceps

13984

Dental instruments; elevator type Bein

13985

Dental instruments; elevator type Flohr

13986

Dental instruments; elevator type Winter

13987

Dental-Trays

13999

B1. 1

Dental instruments; dental forceps, type London College

58268

Dental instruments; dental forceps, type Merian

58269

Dental instruments; dental scissors

58283

Dental instruments; dental scissors, crown

58284

Materials, finish and testing of medical instruments; explorers,

58298 filling and carving instruments

Materials, finish and testing of medical instruments; scalers

58298

Teil 16

Materials, finish and testing of medical instruments;

58298 extracting forceps

Teil 17

Materials, finish and testing of medical instruments;

$58 \quad 298$ elevator, dental

Teil 18

Lighting of dental operatories and laboratories; recommendations

67505 
Surgical instruments

Tooth forceps, for upper incisor

$4272-51$

Tooth forceps, for upper small molar

$4273-51$

Tooth forceps, for lower small molar

4274-51

Tooth forceps, for upper large molar, right

$4275-51$

Tooth forceps, for upper large molar, left

Root forceps, for lower root, narrow

$4277-51$

Root forceps, for upper root

4278.51

Volkmann's scaler

4288.51

Bruns' scaler

$4289-51$

Straight elevator, Lecluse type

10490-52

Curved root elevator, Winter type

$10491 \cdot 52$

Dentist's crown forming

Pliers, round nose type

$14671-55$

Pliers, long flat type

14674.55

Surgical instruments

Root elevator, Vajna type

14680-53

Balogh's scaler

14683-53

Handle for dentist's mirror

14684-51

Root elevator, Barry type

14681-53

Dentist's mirror

14685-53

Tweezers for root plugging

14686-53

Tweezers

14687.53

Explorer

14688-53

Scaler

14689-53

Excavator, double ended

14690.53

Plastic fillers

14691-53

Dentist's retractor, Balogh type

14692-53

Cement spatula

14694-53

Lip retractor

$14695-53$ 
Title

Number

Acrylic resin teeth

8022.1976

Alginate dental impression material

$6036-1970$

Articulators, dental

$5185 \cdot 1969$

Bands, matrix, dental, No. 1 and 2

$7467 \cdot 1974$

Baseplate, dental

8020-1976

Burnisher, dental, No. BRN $1 / 2$

$5005-1968$

Carriers, amalgam, dental, No. 1 and 2

$5576-1970$

Carvers, dental, No. CAR $1 / 2,3 / 4$ and 5/6

$5017 \cdot 1968$

Chair, dental

6116-1971

Chisel, osseous, dental

7676-1975

Chisels, dental

3889.1967

Clamp, flask, dental

$5217 \cdot 1969$

Copper phosphate-zinc phosphate dental cement

6043-1970

Cutter, distal arch wire, dental

$6822 \cdot 1972$

Dental artificial stone

8019.1976

Dental casting gold alloys

4799-1968

Dental casting investment for gold alloys

$7425-1974$

Dental cobalt chromium casting alloys

$7225-1974$

Dental gold alloy wire

3578-1966

Dental gold foil

$3610-1966$

Dental gold solders

3571.1966

Dental impression compound

$6038 \cdot 1970$

Dental impression plaster

$6556-1972$

Dental inlay casting wax

$6888 \cdot 1973$

Dental laboratory plaster

$6555 \cdot 1972$

Dental mercury

$4705-1968$

Dental modelling wax

7966-1976

Dental silicate cement

$6884-1973$

Dental porcelain 8571-1977

Dental sticky wax 8021-1975

Dental white gold alloys 5954-1970

Denture base polymer $6887 \cdot 1973$

Dimensions for dental cable arm

$6182 \cdot 1971$ 
Dimensions for transmission coupling (slip-joint) to dental handpieces

$5830-1970$

Elevators, dental, No. 1, 2 and 3

$4975-1968$

Enamel, hatchet, dental No. EH 1/2

4689-1968

Engine, dental electric

5941-1970

Excavators, dental, No. EX 1/2, 3/4, 5/6, 7/8, $9 / 10,11 / 12$ and $13 / 14$

4715.1968

Exolevers, apical, dental, No. 1, 2 and 3

$7677-1975$

Fitting dimensions for dental burs and cutters

$6462 \cdot 1972$

Flasks, dental $5227-1969$

Foot-operated dental engine

Forceps, extraction, dental, lower incisors, cuspids and bicuspids

6858-1972

Forceps, extraction, dental, lower incisors, cuspids and bicuspids, left

6826-1972

Forceps, extraction, dental, lower incisors and canines, children

8045-1976

Forceps, extraction, dental, lower molars

$6823-1972$

Forceps, extraction, dental, lower molar, children

8044-1976

Forceps, extraction, dental, lower molar, Hawk's bill, No. 1

$4977 \cdot 1968$

Forceps, extraction, dental, lower wisdom tooth

6824-1972

Forceps, extraction, dental, upper anteriors, No. 1 and 2

4976-1968

Forceps, extraction, dental, upper cuspids and bicuspids

6825-1972

Forceps, extraction, dental, upper incisors and canines, children

8046-1976

Forceps, extraction, dental, upper molars, children

$8047 \cdot 1976$

Forceps, extraction, dental, upper molars, left

$6827-1972$

Forceps, extraction, dental, upper molars, right

6828-1972

Forceps, extraction, dental, upper root, medium beak

$6867-1972$

Forceps, extraction, dental, upper root, narrow beak

$6856 \cdot 1972$

Forceps, extraction, dental, upper root, wide beak

6859.1972

Forceps, extraction, dental, upper wisdom tooth

$6866-1972$

Forceps, Rongeur, dental

8207.1976

Forceps, rubber dam clamp and cotton roll clamp, dental

$6402 \cdot 1971$

Frame, rubber dam, dental

$5965-1970$

General requirements for control unit for air turbine, dental

6846-1972

General requirements for cutting type dental instruments

3887-1966

General requirements for forceps, extraction, dental

6868-1972 
Glossary of terms relating to dentistry

Part I: Dental equipment

7348-1974

Part II: Dental instruments and accessories

$7348-1975$

Part III: Dental materials

$7348 \cdot 1975$

Holder, cotton wool, dental

$6292 \cdot 1971$

Holder, wire and broach, dental

$5997-1970$

Hot plate, wax levelling, dental

$3875-1966$

Instruments, plastic filling, dental:

Part I: Designation numbers $1,3,4,5$ and 6

$3890-1967$

Part II: Designation numbers 12, 20, 21, 46, 47, 153 and 183

$3890-1967$

Knife, plaster, dental

$3876 \cdot 1967$

Knives, gingivectomy, dental

7833.1975

Mandrels, dental, No. 1, 2 and 3

$5582 \cdot 1970$

Method for chemical analysis of silver-tin dental and amalgam alloy

6889.1973

Method for chemical analysis of dental, gold alloys

Part I: Determination of gold, silver, copper, palladium and platinum

Part II: Determination of nickel and zinc

$6890-1973$

(Part I)

6890.1975

(Part II)

Mouth mirror and mouth mirror handle, dental

$6020-1970$

Needles, hypodermic, dental

$5180-1969$

Nippers, cutting, dental

$7476-1974$

Occlusal plane guide, dental

$5763-1970$

Pedestal cuspidor

$5645-1970$

Plaster shears, dental

$3878-1967$

Pliers, angle ribbon arch with groove, dental

$7781 \cdot 1975$

Pliers, angle wire bending, dental

$6829-1972$

Pliers, anterior band forming, double beak, dental

8528-1977

Pliers, arrowheaded clasp forming, dental

$7139-1973$

Pliers, band forming, dental

$5540-1970$

Pliers, band forming, dental Peak's pattern upper right and lower left, and upper left and lower right

$7141-1973$

Pliers, band removing, anterior, dental

$7339-1974$

Pliers, band removing, posterior, dental

$7338-1974$

Pliers, bar bending, dental

4315-1967

Pliers, clasp adjusting, dental

7334. 1974

Pliers, closing loop, Nance type, dental

$7335 \cdot 1974$ 
Pliers, spring forming, dental

$7333-1974$

Pliers, stretching and contouring, dental

4319-1967

Pliers, tie back, Nance type, dental

7336-1974

Pliers, workroom, dental

$5828 \cdot 1970$

Pluggers, root canal, dental, No. PLG 1, 2 and 3

5179.1969

Press, flask, dental

$5181 \cdot 1969$

Probes, dental, No. PR 1, 2, 3, 4, 6, 6/7 and 8/9

4716.1968

Punch, rubber dam, dental

$5879 \cdot 1970$

Pusher, band, dental, Mershon's pattern

8284-1976

Receiver, waste, dental

$6282 \cdot 1971$

Reflector and cheek retractor, dental

$5958 \cdot 1970$

Retainers, matrix, dental, No. 1 and 2

$6815 \cdot 1972$

Scalers, dental, No. SC $1 / 2,3 / 4$ and $5 / 6$

4714-1968

Scissors, crown, dental, straight and curved on flat

5212.1969

Scissors, dental, No. 1, straight and curved on flat

5211-1969

Separator, double-bow, dental

$6857-1972$

Silver-tin dental amalgam alloy

4704-1968

Spatula, dental

3888-1967

Spatula, plaster, dental, curved and straight

4679-1968

Spatula, plastics, clear and colourless, dental

$5541 \cdot 1970$

Spatula, wax, dental, No. 1

3879.1967

Spatula, wax, dental, No. 2

4680.1968

Spoons, cutting, dental, No. $1 / 2,3 / 4$ and 5/6

5004-1968

Stool, operating, dental

8346-1977 
Surveyor, cast, dental

Syringe, air and water, dental

6814.1972

Syringe, hypodermic, cartridge, dental, pivot breech cap type

5584-1970

Syringe, hypodermic, dental for interchangeable needles

6525.1972

Syringe, water, self-filling, dental

6811-1972

Trays, instrument-cabinet, dental

7066-1973

Tweezers, dental, No. 1, 2 and 3

64.04-1971

Tweezers, extraction, dental

8527.1977

Tweezers, soldering

$8283-1976$

Unit, dental

5023-1969

Wax, knife, dental

$3877-1967$

Zinc oxide-eugenol dental cement

$6039-1970$

Zinc oxide-eugenol dental impression paste

$6038-1970$

Zinc phosphate dental cement

$6035-1970$

Guide for the use of dental materials

$8850-1978$

Autopolymerizing (acrylic) resins for dental use

8864.1978

Tooth designation for dental purposes (two-digit system)

$8815-1978$

STANDARDS INSTITUTION OF ISRAEL (SII)

\begin{tabular}{ll}
\hline \multicolumn{1}{c}{ Title } & Number \\
\hline Toothbrushes made of plastomers & 863 \\
Dental casting gold alloy & 1066 \\
Alloy for dental amalgam & $1402 / 3$ \\
\hline
\end{tabular}


Frist and Slip-Joint $\mathrm{K}_{\text {}}$ for Electric Dental Engine

T $5105-1962$

Belts for Electric Dental Engine

T $5106-1976$

Stand for Electric Dental Engine

T 5107.1976

Bracket Arm for Electric Dental Engine

T 5108.1976

Electric Dental Engines

T 5109-1971

Dental Barł

T 5201.1976

Pulp Canal Reamers

T 5202.1979

Mandrel for Dental L'se

T 52041960

Dental Pulp Canal Cleansers

T 5205.1976

Dental Broaches

T 5206-1978

Pulp Canal Reamers for Angle Hand-pieces

T 5207.1979

Peeso's Root Reamers for Dental L'se

T 5208-1979

Dental Carborundum Theels

T $5209-1979$

Dental Carborundum Points

T 5210-1979

Dental Pincettes

T 5401-1961

Dental Explorers

T 5402.1979

Dental Chisel

T 5403.1979

Dental Spoon Excarator

T 5404-1979

Dental Plastic

T 5405.1979

Dental Scalers

T 5406-1979

Dental Elevators

T 5407.1978

Dental Bone Files

T 5408.1970

Dental Broach-Holders

T 5409.1978

Dental Forceps

T 5410.1970

Dental Crown Scissors

T 5411.1970

Dental Operating Knives

T 5412-1970

Dental Curettes

T 5413.1970

Dental Tax Spatula

T 54141970

Gingival Applicator

T 5415.1970

Dimension for Dental Hand-Piece

T 5901.1976

Dental Spittoon

T 5902.1979

Dental Mirror and its Holders

T 5903.1958

Nickel-Chromium Alloy Hires for Dental Use

T 6101-1976 
Nickel-Chromium Alloy Plates for Dental Use

T $6102-1976$

Stainless Steel Wires for Dental Use

T 6103-1976

Cobalt-Chromium Alloy Wires for Dental Use

T 6104-1976

Dental Wrought Gold-Silver-Palladium Alloy

T $6105-1974$

Dental Casting Gold-Silver-Palladium Alloy

T 6106-1974

Gold-Silver-Palladium Alloy Solders for Dental Use

T 6107-1974

Dental Silver Casting Alloy

T 6108-1968

Dental Amalgam Alloy

T $6109-1979$

Dental Fusible Alloy

T 6110-1965

Dental Silver Solders

T $6111-1968$

Dental Mercuries

T $6112-1968$

Dental Casting $14 \mathrm{~K}$ Gold Alloy

T 6113-1976

Plus Metals for Dental Casting 14 K Gold Alloy

T 6114-1976

Dental Casting Cobalt Chromium Alloy

T 6115-1979

Acrylic Denture Base

T 6501.1976

Dental Paraffin Wax

T 6502.1976

Dental Inlay Casting Wax

T $6503-1979$

Dental Impression Compound

T 6504-1979

Alginate Impression Material

T 6505-1979

Resin Teeth

T 6506-1976

Temporary Stoppings for Dental Use

T 6507-1976

Dental Heat Curing Acrylic Resin for Crown

T 6508-1979

Dental Self-Curing Acrylic Resin for Filling

T $6509-1979$

Dental Base Plates

T $6510-1979$

Porcelain Teeth for Plate Denture

T $6511-1976$

Dental Casting Investment

T 6601-1979

Dental Zinc Phosphate Cement

T 6602-1979

Dental Silicate Cement

T $6603-1976^{*}$

Dental Calcined Gypsum

T 6604-1976

Dental Hardness Gypsum

T $6605-1976$

* English version is available 
Dental instruments. Tooth extracting forceps; General requirements and tests.

PN-76/Z-56102

Dental instruments. Plaster spoon.

PN-53/Z-56109

Dental instruments. Borers; Specifications.

PN-75/Z-56507

Dental instruments. Shanks for angled and straight handpieces.

PN-73/Z-56599

Medical instruments. Handpieces angled and straight. Technical requirements and tests.

PN-73/Z-56600

Dental grinder with bipolar single-phase induction motor. General requirements and tests.

BN-75/5919-10

Dental instruments. Tooth extracting forceps.

BN-74/5921.02

Dental instruments. Root elevators. Technical requirements and tests.

PN-75/Z-5614.3

Dental instruments. Elevators for lower roots, blunt.

BN-75/5922-02

Dental instruments. Root elevators type Bein.

BN-75/5922-03

Dental instruments. Bone chisels. General requirements and tests.

BN-76/5922-04

Medical instruments. Dental forceps

BN-74/5923.02

Dental instruments. Pluggers, excavators, explorers. General requirements and tests.

BN-71/5923-05

Dental instruments. One-sided pluggers, curved.

BN.71/5923-06

Dental instruments. Two-sided pluggers, curved.

BN.77/5923-07

Dental instruments. Canal pluggers, straight.

BN-71/5923-08

Dental instruments. Excavators.

BN.71/5923.09

Dental instruments. Explorers.

BN-77/5923-10

Dental instruments. Spoons and scalers. Requirements and tests.

BN-77/5923-11.01

Medical instruments. Spoons. Dimensions.

BN-78/5923-11.02

Medical instruments. Scalers, sickle shape. Dimensions.

BN-77/5923-11.03

Medical instruments. Scalers-cleavers. Dimensions.

BN-77/5923-11.04

Medical instruments. Scalers, hook shape. Dimensions.

BN.77/5923-11.05

Dental instruments. Two-sided spatula shape instruments for teeth filling.

BN.74/5923.12

Dental instruments. Borers. Dimensions.

Instruments and dental equipment. Borer, straight handpiece, contra angle handpiece, cable arm, motor, drilling machine: joining dimensions.

Dental instruments. Pliers. General requirements and tests. 
Dental instruments. Round nose pliers.

BN-74/5926-03

Dental instruments. Sling, clasp pliers type McKellops.

BN-68/5926-04

Dental instruments. Wire bending pliers type Aderer.

BN-68/5926-05

Dental instruments. Contouring pliers.

BN-74/5926.06

Dental instruments. Pin roughening, cutting and bending pliers, ordinary.

BN-68/5926-07

Dental instruments. Cutting wire pliers, frontal.

BN-68/5926.08

Dental instruments. Crown stretching pliers.

BN-74/5926.09

Dental instruments. Universal, prosthodontic pliers, pointed.

BN-68/5926-10

Dental instruments. Clasp bending pliers.

BN-74/5926.11

Dental instruments. Clasp and arch bending pliers type Waldsachs.

BN.68/5926-12

Dental instruments. Crown forming pliers type Tryfus.

BN-68/5926-13

Dental instruments. Prosthodontic contouring pliers type Triplex.

BN-68/5926-14

Dental instruments. Plaster spatula.

BN-74/5926-15

Dental instruments. Ring forming pliers type How.

BN.74/5926-16

Dental instruments. Wax knife

BN.75/5926.17

Dental instruments. Plaster knife.

BN-74/5926-18

Dental equipment. Expansion screws.

BN-76/5928-01 
Oxygen for medical use

CKS 40-1966

Nitrous oxide for medical use

CKS 41-1966

Oxygen and carbon dioxide mixtures for medical use

CKS 66.1967

Plaster of Paris for dental use

CKS 72-1967

Hydrocolloidal impression materials

CKS 87-1967

Dental mercury (metric units)

CKS 321-1972

Dental inlay casting wax

CKS 395-1973

\section{Production of injections for dental use:}

The production of lignocaine and noradrenalin injection

for dental use

SABS 143-1971

The production of lignocaine and adrenalin and noradrenalin for dental use

SABS 659-1973

Local anaesthetics for dental use (see also SABS 955/961-1969)

SABS $817 / 818.1973$

The production of lignocaine hydrochloride injection for dental use (metric units)

Propoxycaine hydrochloride (metric units)

Local anaesthetics for dental use (metric units) (see also SABS 817/818-1973).

The production of lignocaine and adrenalin injection for dental use (metric units)

Leyonordefrin (metric units)

Mepivacaine hydrochloride (metric units)

The production of mepivacaine hydrochloride and levonordefrin injection for dental use (metric units)

The production of procaine $(2 \% \mathrm{~m} / \mathrm{v})$ and adrenalin injection for dental use (1:80 000) (metric units)

The production of propoxycaine hydrochloride injection (metric units)

The production of propoxycaine and procaine hydrochloride and levonordefrin injection for dental use (metric units)

Production of single use hypodermic needles (sterile packed) for dental cartridge syringes

Production of mepivacaine hydrochloride injections for dental use 
Title

Number

Lighting in dental operatories

Spri 55101

Dental operation chair/General requirements

Spri 55102

(ISO/DIS 4083)

Dental instrument trays

Spri 55351

Fitting dimensions for burs and cutters used in dentistry

Spri 55401

Dental burs and cutters-Nominal sizes and designation of working parts

Spri 55402

Dental burs and cutters-Dimensions of working parts and overall length, requirements for run-out (eccentricity)

Spri 55403 and surface roughness

(ISO/DIS 3823)

Dental handpieces-Coupling dimensions

Spri 55431

(ISO/DIS 3964)

Dental root canal reamers and files, Part 1: Nominal

Spri 55801

sizes, dimensions and colour coding

(ISO/DIS 3630/1)

Mercury for dental use

Spri 56201

Dental zinc oxide/eugenol filling materials

Spri 56231

(ISO/DIS 3106-1974)

Dental zinc oxide/eugenol cementing materials

Spri 56241

(ISO/DIS 3107-1974)

Dental zinc phosphate cement

Spri 56242

(ISO/DIS 1566)

Dental silicate cement (hand-mixed)

Spri 56343

(ISO/1565-1978)

Dental carboxylate cement

Spri 562-45

Dental inlay casting wax

Spri 56421

(ISO/R-1561-1970)

Denture base resin

Spri 564 61

(ISO/1567-1978)

Synthetic resin teeth

Spri 564 51

(ISO/DIS 3336)

Alginate dental impression material

Spri 56471

(ISO/DIS 1563)

Tooth designation for dental purposes-Two-digit system

Spri 56901

(ISO/DIS 3950)

Copies of above Standards may be obtained from a National member of ISO or from Spri (The Swedish Planning and Rationalization Institute o Health and Social Services) Fack, S-102 50 Stockholm, Sweden. 


\section{References}

Paffenbarger, G. C. and Kumpula, M., Composition, Work and Interrelation of International Organizations Engaged in the Standardization of Dental Materials and Therapeutic Agents. Internat Dent J 15:571, December 1965.

$\therefore$ Souder, W. H., Measurements and Application of Certain Physical Properties of Amalgam. J. Dent Res 7:173, June 1927.
3. Souder, Wilmer H. and Peters, Chauncey, G., An Investigation of the Physical Properties of Dental Materials. Dent Cosmos 62:305, March 1920.

4. Taylor, N. O., Specification for Dental Amalgam Alloys: Report to the Scientific Foundation and Research Commission of the American Dental Association. J Am Dent Assn 17:112 January 1930. 


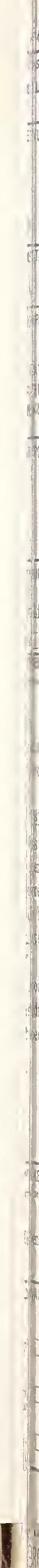




\section{DEPT. OF COMM. \\ IOGRAPHIC DATA SHEET}

LE AND SUBTITLE

Organizations Engaged in Preparing Standards for Dental Materials and Therapeutic Agents with a List of Standards HOR(S)

C. Paffenbarger, N. W. Rupp, and Margaret Malmstedt IFORMING ORGANIZATION NAME AND ADDRESS

TIONAL BUREAU OF STANDARDS

PARTMENT OF COMMERCE

SHINGTON, DC 20234

$\partial x^{2}$

NSORING ORGANIZATION NAME AND COMPLETE ADDRESS (street, City, state, ZIP)
5. Publication Date

April 1980

6. Pertoming Organization Code

8. Performing Organ. Report No.

10. Project Task/Notk Unit No:

11. Contract/Grant No.

13. Type of Report \& Period Covered

14. Sponsoring Agency Code

PPLEMENTARY NOTES

Lbrary of Congress Catalog Card Number: 80-600041

Document describes a computer program; SF-185, FIPS Software Summary, is attached.

STRACT (A 200-word or less factual summary of most significant information. If document includes a significant bibliography or rature survey, mention it here.)

The first specification for dental materials was prepared by Wilmer Souder, a physicist at the National Bureau of Standards, in 1927. From.stemmed the specification and certification programs of the American Dental ciation (1930) and all of the similar national and international programs.

The Federation Dentaire Internationale (FDI) was the first in the international Ld (1953). Today the International Organization for Standardization (ISO) through Technical Committee 106-Dentistry, organized in 1963, is the prime international icy formulating specifications for dental materials and devices. The FDI role by sement with ISO/TC106 is the preparation for standards on clinical evaluations, siological test methodology, on the preparation of informative reports on dental erials and therapeutic agents and on the proper methods of using them.

Today there are 15 international and national agencies that have prepared It 900 specifications for dental materials and devices. These agencies and their resses are listed, with a brief history of each, together with a list of the ifications and standards that they have promulgated.

Y WORDS (six to twelve entries; alphabetical order; capitalize only the firat letter of the first key word unleos a proper namo; arated by semicolons)

tal agencies; devices; history; materials; programs; specifications.

For Official Distribution. Do Not Release to NTIS

J Order From Sup. of Doc., U.S. Government Printing Office, Washington, DC 20402, SD Stock No. SNÓ03-003-02163-6

] Order From National Technical Information Service (NTIS), Springfield, VA. 22161

\begin{tabular}{|l|c|}
\hline $\begin{array}{l}\text { 19. SECURITY CLASS } \\
\text { (THIS REPORT) }\end{array}$ & $\begin{array}{c}\text { 21. NO. OF } \\
\text { PRINTED PAGES } \\
\text { UNCLASSIFIED }\end{array}$ \\
\hline $\begin{array}{l}\text { 20. SECURITY CLASS } \\
\text { (THIS PAGE) }\end{array}$ & $\begin{array}{c}22 . \text { Price } \\
\$ 3.50\end{array}$ \\
UNCLASSIFIED & USCOMM.DC \\
\hline
\end{tabular}




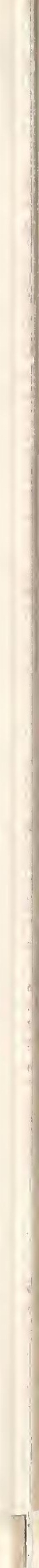




\section{NBS TECHNICAL PUBLICATIONS}

\section{PERIODICALS}

OURNAL OF RESEARCH-The Journal of Research of the Tational Bureau of Standards reports NBS research and developlent in those disciplines of the physical and engineering sciences in hich the Bureau is active. These include physics, chemistry, ngineering, mathematics, and computer sciences. Papers cover a road range of subjects, with major emphasis on measurement rethodology and the basic technology underlying standardization. Iso included from time to time are survey articles on topics osely related to the Bureau's technical and scientific programs. is a special service to subscribers each issue contains complete tations to all recent Bureau publications in both NBS and nonBS media. Issued six times a year. Annual subscription: domestic 17: foreign \$21.25. Single copy, \$3 domestic; $\$ 3.75$ foreign.

IOTE: The Journal was formerly published in two sections: Secon A "Physics and Chemistry" and Section B "Mathematical ciences."

JMENSIONS/NBS-This monthly magazine is published to inform scientists, engineers, business and industry leaders, teachers, tudents, and consumers of the latest advances in science and echnology, with primary emphasis on work at NBS. The magazine lighlights and reviews such issues as energy research, fire protecion, building technology, metric conversion, pollution abatement, tealth and safety, and consumer product performance. In addiion, it reports the results of Bureau programs in measurement tandards and techniques, properties of matter and materials, ngineering standards and services, instrumentation, and utomatic data processing. Annual subscription: domestic \$11; oreign $\$ 13.75$

\section{NONPERIODICALS}

Monographs-Major contributions to the technical literature on various subjects related to the Bureau's scientific and technical acivities.

Handbooks-Recommended codes of engineering and industrial ractice (including safety codes) developed in cooperation with inerested industries, professional organizations, and regulatory sodies.

Special Publications-lnclude proceedings of conferences sponsored by NBS, NBS annual reports, and other special publications appropriate to this grouping such as wall charts, pocket cards, and bibliographies.

Applied Mathematics Series-Mathematical tables, manuals, and studies of special interest to physicists, engineers, chemists, biologists, mathematicians, computer programmers, and others engaged in scientific and technical work.

National Standard Reference Data Series-Provides quantitative data on the physical and chemical properties of materials, compiled from the world's literature and critically evaluated. Developed under a worldwide program coordinated by NBS under the authority of the National Standard Data Act (Public Law 90-396)
NOTE: The principal publication outlet for the foregoing data is the Journal of Physical and Chemical Reference Data (JPCRD) published quarterly for NBS by the American Chemical Society (ACS) and the American Institute of Physics (AIP). Subscriptions, reprints, and supplements available from ACS, 1155 Sixteenth St., NW, Washington, DC 20056

Building Science Series-Disseminates technical information developed at the Bureau on building materials, components, systems, and whole structures. The series presents research results, test methods, and performance criteria related to the structural and environmental functions and the durability and safety characteristics of building elements and systems.

Technical Notes-Studies or reports which are complete in themselves but restrictive in their treatment of a subject. Analogous to monographs but not so comprehensive in scope or definitive in treatment of the subject area. Often serve as a vehicle for final reports of work performed at NBS under the sponsorship of other government agencies.

Voluntary Product Standards-Developed under procedures published by the Department of Commerce in Part 10. Title 15, of the Code of Federal Regulations. The standards establish nationally recognized requirements for products, and provide all concerned interests with a basis for common understanding of the characteristics of the products. NBS administers this program as a supplement to the activities of the private sector standardizing organizations.

Consumer Information Series-Practical information, based on NBS research and experience, covering areas of interest to the consumer. Easily understandable language and illustrations provide useful background knowledge for shopping in today's technological marketplace.

Order the above NBS publications from: Superintendent of Documents, Government Printing Office, Washington, DC 20402.

Order the following NBS publications-FIPS and NBSIR's-from the National Technical Information Services, Springfield, VA 22161.

Federal Information Processing Standards Publications (FIPS PUB)-Publications in this series collectively constitute the Federal information Processing Standards Register. The Register serves as the official source of information in the Federal Government regarding standards issued by NBS pursuant to the Federal Property and Administrative Services Act of 1949 as amended, Public Law 89-306 (79 Stat. 1127), and as implemented by Executive Order 11717 (38 FR 12315, dated May 11, 1973) and Part 6 of Title 15 CFR (Code of Federal Regulations).

NBS Interagency Reports (NBSIR) - A special series of interim or final reports on work performed by NBS for outside sponsors (both government and non-government). In general, initial distribution is handled by the sponsor; public distribution is by the National Technical Information Services, Springfield, VA 22161, in paper copy or microfiche form.

\section{BIBLIOGRAPHIC SUBSCRIPTION SERVICES}

The following current-awareness and literature-survey bibliographies are issued periodically by the Bureau:

Cryogenic Data Center Current Awareness Service. A literature survey issued biweekly. Annual subscription: domestic \$25; foreign $\$ 30$.

Liquefied Natural Gas. A literature survey issued quarterly. Annual subscription: $\$ 20$
Superconducting Devices and Materials. A literature survey issued quarterly. Annual subscription: $\$ 30$. Please send subscription orders and remittances for the preceding bibliographic services to the National Bureau of Standards, Cryogenic Data Center (736) Boulder, CO 80303. 
U.S. DEPARTMENT OF COMMERCE

National Bureau of Standards

Washington, D.C. 20234

OFFICIAL BUSINESS

Penalty for Private Use, $\$ 300$
POSTAGE ANO FEES PAIO
U.5. OEPARTMENT OF COMMERCE

COM-215

SPECIAL FOURTH-CLASS RATE

BOOK

8 